\title{
Upgrading of Raw Oil Into Advanced Fuel
} Task 5

\section{Topical Report}

October 1991

Work Performed Under Contract No.: DE-AC21-88MC25020

For

U.S. Department of Energy

Office of Fossil Energy

Morgantown Energy Technology Center

Morgantown, West Virginia

By

Lummus Crest, Inc.

MISTER

Bloomfield, New Jersey 


\section{DISCLAIMER}

This report was prepared as an account of work sponsored by an agency of the United States Government. Neither the United States Government nor any agency thereof, nor any of their employees makes any warranty, express or implied, or assumes any legal liability or responsibility for the accuracy, completeness or usefulness of any information, apparatus, product, or process disclosed, or represents that its use would not infringe privately owned rights. Reference herein to any specific commercial product, process, or service by trade name, trademark, manufacturer, or otherwise, does not necessarily constitute or imply its endorsement, recommendation, or favoring by the United States Government or any agency thereof. The views and opinions of authors expressed herein do not necessarily state or reflect those of the United States Government or any agency thereof.

This report has been reproduced directly from the best available copy.

Available to DOE and DOE contractors from the Office of Scientific and Technical Information, P.O. Box 62, Oak Ridge, TN 37831; prices available from (615)576-8401, FTS 626-8401.

Available to the public from the National Technical Information Service, U.S. Department of Commerce, 5285 Port Royal Rd., Springfield, VA 22161. 


\title{
Upgrading of Raw Oil Into Advanced Fuel Task 5
}

\author{
Topical Report
}

Work Performed Under Contract No.: DE-AC21-88MC25020

\author{
For \\ U.S. Department of Energy \\ Office of Fossil Energy \\ Morgantown Energy Technology Center \\ P.O. Box 880 \\ Morgantown, West Virginia 26507-0880
}

\author{
By \\ Lummus Crest, Inc. \\ 1515 Broad Street \\ Bloomfield, New Jersey 07003
}

October 1991 
Page No.

List of Figures ii

List of Tables iii

\subsection{EXECUTIVE SUMMARY}

1.1 Background \& DOE Perspective 1

1.2 Contract Objectives 2

1.3 Task Breakdown Structure 2

2.0 EXPERIMENTAL PROCEDURES

2.1 Overview 4

2.2 Pilot Plant Fixed-Bed Hydrotreating Unit 4

2.3 Pilot Plant Expanded-Bed LC-Fining Unit 6

2.4 4-in Batch Fractionation Unit 8

2.5 Equilibrium Flash Vaporization Pilot Unit 8

2.6 Pilot Plant Clay Treating Unit 9

2.7 Analytical Methods and Calculation Procedures $\quad 9$

\section{$\begin{array}{ll}3.0 & \text { FEEDSTOCK ANALYSES }\end{array}$}

4.0 PILOT PLANT SAMPLE PREPARATION OPERATIONS 36

4.1 Overview 36

4.2 LC-Fining Operations $\quad 37$

4.3 Fixed-Bed Hydrodenitrogenation Operations $\quad 39$

4.4 Fixed-Bed Selective Hydrocracking Operations 41

4.5 Post-Hydrotreatment Operations 41

4.5.1 Batch Fractionation 41

4.5.2 Distillate Product Blending 43

4.5.3 Clay Treating 43

$\begin{array}{lll}5.0 & \text { HEDF ASSAYS } & 47\end{array}$

6.0 REFERENCES $\quad 51$

7.0 ACKNOWLEDGEMENTS 


\section{LIST OF PIGURES}

Figure No.

2. 3-1

3. 1-1

3. $1-2$

3. $1-3$

3.1-4

3. 1-5

3. 1-6

$3.1-7$

$3.1-8$

3. 1-9

$3.1-10$

$3 \cdot 1-11$

$3 \cdot 1-12$

3. 1-13

3. 1-14

3. $1-15$

$3.1-16$

$3.1-17$

$3.1-18$
Page No

LC-Fining Pilot Plant Schematic

Consolidated ASTM D86/1160 Distillations of Dewatered COALITF.

ASTM Distillations of Synfuel Feedstocks 13

Wt\% Distillate Yield As A Function of VABP of Cut 15

H/C Atomic Ratio of COALITE Distillate Cuts As A 20 Function of VABP of Cut

API Gravity of COALITE Distillates As A Function 21 of VABP of Cut

Nitrogen Content As A Function of VABP of Cut 22

Wt\% Oxygen Content As A Function of VABP of Cut 23

Wt\% Sulfur Content As A Function of VABP of Cut 24

PONA Analysis of Selected COALITE Distillates 25

As A Function of VABP of Cut

$\begin{array}{ll}\text { Hydrogen Distribution by HNMR Spectroscopy } & 27\end{array}$ As A Function of VABP of Cut

Calculated Carbon Distributions From HNMR 28 As A Function of VABP of Cut

H/C Ratios From HNMR Spectroscopy 29

As A Function of VABP of cut

Bromine No As A Function of VABP of Cut 30

Refractive Index 220C As A Function of VABP of Cut 31

API Gravity As A Function of Refractive Index 32

H/C Atomic Ratio As A Function of Refractive Index 33

Hydrogen Aromaticity As A Function of Refractive 34 Index of Distillate Cuts

Carbon Aromaticity As A Function of Refractive 35 Index of Distillate Cuts 


\section{LIST OF TABLES}

Table No.

Table Title

Page No

3.1-1

$3.1-2$

$3.1-3$

$4.2-1$

$4 \cdot 3-1$

$4.4-1$

$4 \cdot 5 \cdot 1-1$

$4 \cdot 5 \cdot 2-1$

$4 \cdot 5 \cdot 3-1$

$5-1$

$5-2$
Analyses of Narrow Boiling COALITE Distillates

14

G.C./M.S. Analysi of 200-550F COALITE

NMR Spectroscopy of 390-650F COALITE

Run 6LCF-14 LC-Fining Production Run Summary

Run 6LCF-5 Fixed-Bed Hydrodenitrogenation Run Summary

Run 6LCF-16 Fixed-Bed Selective Hydrocracking 42 Run Summary

Summary of Batch Distillation of Selectively 44 Hydrocracked LC-Finate Gas Oils

Summary of Optimum Blending Study of HEDF Test 45

Fuel Cuts From Batch Fractionation

Summary of Bentonite Clay Treating of HEDF Test 46 Fuels

Summary of Final COALITE HEDF Test Fuel Properties 48

Summary of Task 3 Screening Program Results

16

26

38

40

49
48 


\subsection{EXECUTIVE SUMMARY}

\subsection{Background \& DOE Perspective}

In April 1988, the Department of Energy (DOE) Morgantown Energy Technology Center (METC) issued a request for proposal (RFP) soliciting a research effort for the "Development of High Energy Density Fuels from Mild Gasification of Coal". ABB Lummus Crest Inc. (LCI), a subsidiary of Asea Brown Boveri Inc., and Amoco 0il Company (AOC) as kEy subcontractor successfully responded to the RFP and entered into a contract (No. DE-AC22-88MC25020) with the DOE on September 30, 1988.

The RFP was predicated on DOE's desire to enhance the development of advanced transportation fuels made from coal via a program to process mild coal gasification (MCG) liquids into high volumetric energy density (HEDF) test fuels. The desired product fuels were to be cost effectively manufactured, have high volumetric energy density, and be hydrocarbon-based for existing and prototype turbine and diesel engines. The sources for these special fuels consist of the abundant and secure indigenous energy resources of coal. Comparison studies were also to be made using other non-petroleum fuels such as shale oil and tar sands bitumen.

METC has concluded that MCG technology has the potential to simultaneousiy satisfy the transportation and power generation fuel needs in the most cost-effective manner. MCG is based on low temperature pyrolysis, a technique known to the coal community for over a century. Most past pyrolysis developments were aimed at maximizing the liquids yield which results in a low quality tarry product requiring significant and capital intensive upgrading.

By properly tailoring the pyrolysis severity to control the liquid yield-liquid quality relationship, it has been found that a higher quality distillate-boiling liquid can be readily "skimmed" from the coal. The resultant liquids have a much higher $H / C$ ratio than conventional pyrolytic tars and therefore can be hydroprocessed at lower cost. These liquids are also extremely enriched in 1-, 2-, and 3-ring aromatics. The co-product char material can be used in place of coal as a pulverized fuel(pf) for power generation in a coal combustor. In this situation where the original coal has a high sulfur content, the MCG process can be practiced with a coal-1ime mixture and the calcium values retained on the char can tie up the unconverted coal sulfur upon of combustion of the char. Lime has also been shown to improve the yield and quality of the MCG liquids.

The development of advanced fuels will provide increased range of volume-limited aircraft/missiles/vehicles and possibly provide a better heat sink than existing liquid fuels for high-speed aircraft. These special fuels would also provide desired characteristics for aircraft/vehicle operations in extreme conditions. Development of these fuels would have civilian and military applications in turbine and/or diesel engines for extended range and uses in remote areas where fuel supply may be difficult to sustain. 
While little R\&D has been conducted on the treatment of coal-derived MCG liquids to produce advanced fuels, significant R\&D efforts have been carried out to produce specification fuels from shale oi? and tar sands bitumen. The major technical challenge in this program is the development of effective methods for treating MCG liquids and in increasing volumetric energy density while still meeting the essential features of the operational fue? specifications.

Processing and upgrading methods are needed to produce good yields of advanced fuels while minimizing overall processing costs. Advanced test fuels of interest must be produced to meet operational requirements reflected in the DOD fuel specifications but may vary in chemical composition so as to increase the volumetric energy density and/or reduce the processing severity.

\subsection{Contract Objectives}

The overall objective of the research effort is the determination of the minimum processing requirements to produce high energy density fuels (HEDF) having acceptable fuel specifications. The program encompasses assessing current technology capability; selecting acceptable processing and refining schemes; and generating samples of advanced test fuels.

The specific objectives are:

- Conduct a technical and economic assessment of promising processing and upgrading methods to convert raw products from mild coal gasification into advanced high volumetric energy density test fuels for aviation turbines and diesel engines;

- Conduct screening tests of alternative processing methods; and

- Generate and deliver test quantities, ca., 100 gallons, of advanced fuels from mild coal gasification liquids and other sources such as shale oil or tar sands bitumen.

\subsection{Task Breakdown Structure}

The Phase I Baseline Program is intended to explore the processing alternatives for producing advanced HEDF from two raw synfuel feedstocks, one from Mild Coal Gasification as exemplified by the COALITE process and one from Colorado shale oil. Eight key tasks have been identified as follows:

Task I.D. No.

\section{Task Definition}

Planning and Environmental Permitting

Transporting and Storage of Raw Fuel Sources and Products

Screening of Processing and Upgrading Schemes

Proposed Upgrading Schemes for Advanced Fuel 


$\begin{array}{ll}5 & \text { Upgrading of Raw } 0 i 1 \text { into Advanced Fuel } \\ 6 & \text { Packaging and Shipment of Advanced Fuels } \\ 7 & \text { Updated Technical and Economic Assessment } \\ 8 & \text { Final Report of Phase I Efforts }\end{array}$

This topical report summarizes the operations and results of the Phase I Task 5 sample preparation program. The specific objectives of Task 5 (in addition to the preparation of this topical report) were to:

- Perform laboratory characterization tests on the raw COALITE feed, the intermediate liquids to the required hydroprocessing units and final advanced fuels and byproducts; and

- Produce a minimum of 25-gal of Category I test fuel for evaluation by DOE and its contractors. 


\subsection{EXPERIMENTAL PROCEDURES}

\subsection{Overview}

The Task 5 Work Statement called for the production of gallon quantities of test fuel bajed on the processing and upgrading schemes delineated in the Task 4 conceptual design study and using laboratory-scale screening equipment. At Lummus' Research \& Development Center (formerly the Engineering Development Center-EDC), sample preparation is carried out in continuous flow, pilot plant equipment. The processing and upgrading schemes for producing HEDF from synfuel feedstocks under the subjeci program include the following unit operations:

o Fixed-bed Distillate Hydrotreating

o $\quad$ Fixed-bed Distillate Hydrocracking

$0 \quad$ Expanded-bed Resid Hydrocracking

- Fractionation

$0 \quad$ Clay Treating

The sample preparation operations were carried out in the following test units:

1. Pilot-Plant Fixed-Bed Hydrotreating Unit

2. Pilot-Plant Expanded-Bed LC-Fining Unit

3. 4-in Batch Fractionation Unit

4. Equilibrium Flash Vaporization Pilot Unit

5. Pilot-Plant Clay Treating Unit

\subsection{Pilot Plant Fixed-Bed Hydrotreating Unit}

The pilot plant fixed-bed hydrotreating unit consists of the pilot plant LC-Fining unit modified to operate in the fixed-bed downflow mode. Two reactors are available and the recycle pumps for expanding the catalyst beds are not energized.

\section{$0 \quad$ Feed Systems}

The fresh oil feed is metered into the top of the first reactor by a positive displacement pump. The oil feed rate is monitored by measuring the weight loss in a feed tank mounted on an electronic scale. The total hydrogen flow is measured using an orifice meter. The individual hydrogen flow rates to the fixed-bed reactors, instrument sensing lines, etc., are measured via high pressure rotameters. All of the "catalytic" or treat gas hydrogen is introduced at the top of the reactor. 
The reactor system consists of two 2.5 in i.d. fixed-bed reactors in series. The reactor and reactor loop are electrically heated with nine temperature controlled circuits for each reactor stage which insures essentially isothermal operation.

\section{$0 \quad$ Product Recovery System}

The net liquid and gas make from the fixed-bed reactors are separated in the high temperature/high pressure (HT-HP) separator. The light oil overhead from the HT-HP separator is condensed and collected in the low temperature/high pressure (LT-HP) separator where it is removed under level control. Quench water is introduced periodically upstream of the condenser to prevent the buildup of sulfides in the lines. The quench water is taken off in a decanter following the LT-HP level controller. The vapors from the LT-HP separator pass through the main pressure control valve which reduces the pressure to atmospheric. The low pressure gas is chilled, scrubbed, sampled, metered and vented. The hydrogen is not currently recycled in the pilot plant unit.

The heavy oil from the HT-HP separator is let down through the level control valve to the low pressure/high temperature (LP-HT) separator which is maintained at about 55 psig. The net flow of heavy oil through the recovery section is low. Heavy oil is recycled from the HT-LP separator back to the HT-HP separator to a) eliminate dead spots which may lead to overheating or undesirable phase separations; and b) increase the flow through the level control valve. A small quantity of stripping gas is introduced into the separator to remove a fraction of the gas oil from the heavy oil. The vapurs from the HT-LP separator are let down to atmospheric pressure and stripped. The stripped gas oil, removed from the stripper by level control, is combined with stripper overhead product and the liquid from the cold trap to form the light oil product. The heavy oil is removed from the HT-LP separator by level control, collected and weighed on an electronic scale.

\section{$0 \quad$ Sampling and Operating Procedure}

Daily operations are usually divided into twelve hour material balance test periods. Routine maintenance and changes in operating conditions are usually made during the day shift. The cold trap liquid is blended in with the light oil receiver liquid prior to analysis. The gas analysis is performed on a composite of equal volume hourly samples. The hydrogen consumption is calculated from the normalized feed and product elemental analyses. The yields of $\mathrm{H}_{2} \mathrm{~S}, \mathrm{NH}_{3}$ and $\mathrm{H}_{2} \mathrm{O}$ are usually obtained by difference from the elemental balances for sulfur, nitrogen and oxygen, respectively.

The operation of this hydroprocessing pilot plant can be tailored to ihe particular objectives of the program and deviations from the above might result when operating the unit under conditions that favor the production of HEDF's from MCG liquids and shale oils. 


\subsection{Pilot Plant Expanded-Bed LC-Fining ${ }^{\text {tm }}$ Unit}

As a co-licensor of the proprietary expanded-bed hydrocracking process known as LC-Finingsm, LCI has the responsibility of providing the process design package to $\mathrm{LC}-$ Fining $\mathrm{gm}^{\mathrm{m}}$ licensees. In support of this effort, several LC-Fining ${ }^{5 m}$ test units are available at EDC. The unit utilized in the Task 3 screening study was a continuous bench-scale system containing an autoclave reactor system to simulate the commercial expanded-bed reactors. Data from this unit was utilized to develop the test conditions of the larger pilot plant reactor system used in Task 5.

The pilot unit, equipped with two reactor stages, has a degree of flexibility and can be operated in alternative hydrogenation modes, fixed-bed upflow or downflow as well as expanded-bed. The following is a description of the major components of the pilot unit.

\section{$0 \quad$ Feed Systems}

The fresh oil feed is metered into the circulating reactor loop by a positive displacement pump. The oil feed rate is monitored by measuring the weight loss in a feed tank mounted on an electronic scale. The total hydrogen flow is measured using an orifice meter. The individual hydrogen flow rates to the LC-Fining reactor, instrument sensing lines, etc., are measured via high pressure rotameters. All of the "catalytic" hydrogen is introduced at the bottom of the reactor.

\section{$0 \quad$ LC-Fining Expanded-Bed Reactor System}

The LC-Fining reactor system (se Figure 2.3-1) consists of 1) a two-stage, expanded-bed in series reactor system; 2) a recycle surge bomb for each reactor stage; and 3) a duplex remote head recycle ("ebullating") pump. The liquid hourly space velocity is calculated based on either the total "thermal reactor" volume which includes the reactor, recycle lines and surge bomb, or on the settled-bed catalyst volume. The LC-Fining reactor and reactor loop are electrically heated with nine temperature controlled circuits for each reactor stage which. insures essentially isothermal operation.

The internal recycle rate can be set to vary bed expansion from about 10 to $35 \%$ of settled bed height. The connecting line to the remote check valve assembly is purged intermittently with a small flow of gas oil from the stripping column.

\section{$0 \quad$ Product Recovery System}

The net liquid and gas make from the LC-Fining reactor loop are separated in the high temperature/high pressure (HT-HP) separator. The light oil overhead from the HT-HP separator is condensed and collected in the low temperature/high pressure (LT-HP) separator where it is removed under level control. Quench water is introduced periodically upstream of the condenser to prevent the buildup of sulficias in the lines. The quench water is taken off in a decanter following the LT-HP 


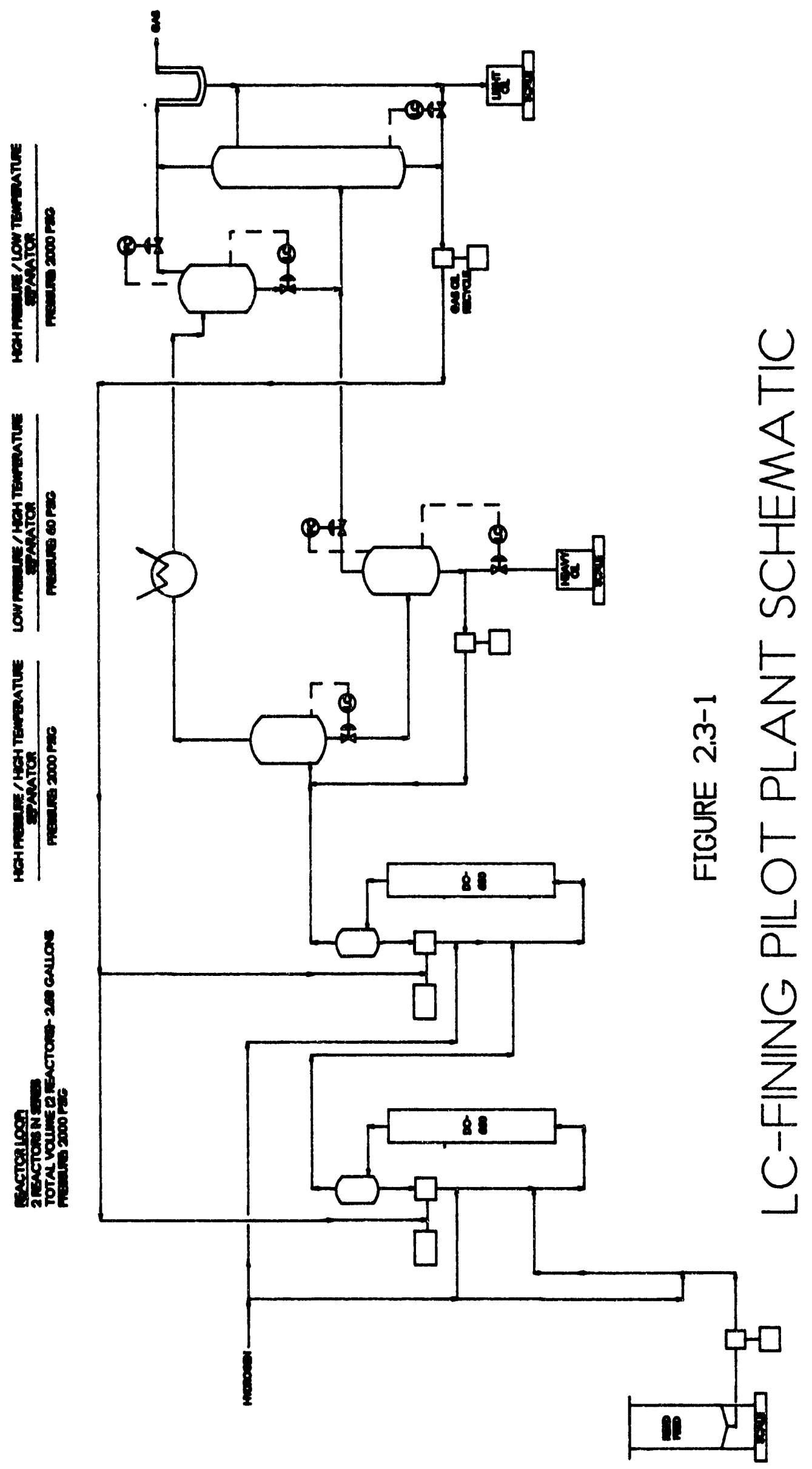


level controller. The vapors from the LT-HP separator pass through the main pressure control valve which reduces the pressure to atmospheric. The low pressure gas is chilled, scrubbed, sampled, metered and vented. The hydrogen is not currentiy recycled in the pilot plant unit.

The heavy oil from the HT-HP separator is let down through the level control valive to the low pressure/high temperature (LP-HT) separator which is maintained at about 55 psig. The net flow of heavy oil through the recovery section is low. Heavy oil is recycled from the HT-LP separator back to the HT-HP separator to a) eliminate dead spots which may lead to overheating or undesirable phase separations; and b) increase the flow through the level control valve. A small quantity of stripping gas is introduced into the separator to remove a fraction of the gas oil from the heavy oil. The vapors from the HT-LP separator are let down to atmospheric pressure and stripped. The stripped gas oil, removed from the stripper by level control, is combined with stripper overhead product and the liquid from the cold trap to form the light oil product. The heavy oil is removed from the HT-LP separator by level control, collected and weighed on an electronic scale.

\section{- Sampling and Orsiating Procedure}

Daily operations are usually divided into twelve hour material balance test periods. Routine maintenance and changes in operating conditions are usually made during the day shift. The cold trap liquid is blended in with the light oil receiver liquid prior to analysis. The gas analysis is performed on a composite of equal volume hourly samples. The hydrogen consumption is calculated from the normalized feed and product elemental analyses. The yields of $\mathrm{H}_{2} \mathrm{~S}, \mathrm{NH}_{3}$ and $\mathrm{H}_{2} \mathrm{O}$ are usually obtained by difference from the elemental balances for sulfur, nitrogen and oxygen, respectively.

The operation of this hydroprocessing pilot plant can be tailored to the particular objectives of the program and deviations from the above might result when operating the unit under conditions that favor the production of HEDF's from MCG liquids and shale oils.

\subsection{4-in Batch Fractionation Unit}

The 4-in Batch Fractionation Unit contains a 4-in diameter by 20-ft SS column containing 20 SS decks of bubble caps, 2 bubble caps per deck equivalent to 8-10 theoretical plates; an automatic variable range reflux head; and an 85-gal reboiler. A vacuum system is capable of operation at reflux head pressures of 5-10 $\mathrm{mm} \mathrm{Hg}$ abs.

\subsection{Equilibrium Flash Vaporization Pilot Unit}

The Equilibrium Flash Vaporization pilot unit is a continuous system for performing single-stage equilibrium flash operations. The unit consists of an 8-in diameter by 14 -in long flash chamber and can process 5-7 gal/hr of liquid feed to a 600F (315C) maximum 
temperature. At the operating vacuum 1 imits (ca., $3-4 \mathrm{~mm} \mathrm{Hg}$ abs), this temperature corresponds to a maximum atmospheric equivalent temperature of about $975 \mathrm{~F}(524 \mathrm{C})$. The unit is a true simple flash with essentially no reflux as the flash chamber walls are electrically heated to at or above the flash temperature.

\subsection{Pilot Plant Clay Treating Unit}

Final purification of finished HEDF products is accomplished by clay treating. A stainlers steel column, $21 / 2-$ in diameter by $5-\mathrm{ft}$ long, was charged with adsorbent (bentonite) and feed was pumped downflow through a backpressure regulater to set a column pressure of $4 \mathrm{psig}$. The thus percolated material is collected directly into a clean 30-gal steel drum that is used for shipment. This minimizes potential contamination from excess handling and liquids transfer. There are no intermediate vessels between the clay column and the sample container. A second pass can be used to obtain further reduction in trace impurities affecting color, corrosion and other jet fuel specifications.

\subsection{Analytical Methods and Calculation Procedures}

The characterization tests consist of performing analytical assays of the COALITE liquids. The COALITE feedstock was analyzed for the following minimal tests:

1. Elemental Analyses

2. Distillation

3. Specific Gravity

4. Hydrocarbon Type Analyses including \% Aromatics

5. Viscosity

6. Aniline Point

7. Bromine Number

8. Heating Value

9. Conradson Carbon Residue (CCR)

10. Solubility in heptane, toluene, quinoline

11. Pour Point

12. Flash Point

13. Diene Number

14. Accelerated Thermal Stability (D.2274)

15. Metals including arsenic

16. Basic Nitrogen

The finished HEDF materials were analyzed for the following properties:

1. Elemental Analyses

2. Specific Gravity

3. Heating Value

4. Distillation

5. Hydrocarbon Type Analys is

6. Flash Point

7. Smoke Point 
8. Pour Point

9. Aniline Point

10. JFTOT Stability

11. D-873 Residue

12. Copper Corrosion

13. Viscosity

14. Existent Gum

Intermediate HEDF products were al so analyzed for selected properties, such as, specific gravity, heating value, hydrocarbon type analysis and elemental analysis.

The calculation procedures basically consist of determining performance criteria for hydroprocessing operations. These typically include percent removal of heteroatoms (hydrodesulfurization-HDS, hydrodenitrogenation-HDN, and hydrodeoxygenation-HDO); percent hydrocracking of $650 \mathrm{~F}+$ components; light gas yield; advanced HEDF yield; and hydrogen consumption. Other correlating parameters of importance include smoke point improvement; API gravity improvement; cetane number improvement; stability and viscosity improvement; percent aromatics reduction; kinetic activation energy and frequency factors. 


\subsection{FEEDSTOCK ANALYSES}

The COALITE MCG liquids consist of a nominal 160-1000F boiling range product from the British COALITE carbonization process. The COALITE process was developed in the early 1900's (1) based on the use of a vertical retort. A COALITE plant built in 1936 at the Bolsover Works of Coalite and Chemical Products Ltd is still in operation and the 1000-gal sample was procured and delivered to LCI in November 1988 by United Coal Company Research Corporation (presently Coal Technology Corporation) of Bristol, VA. The COALITE was produced from a medium coking British coal and is expected to have properties similar to those of U.S. Eastern bituminous coals.

Upon receipt of the 20-drums, 1-quart aliquot samples were taken from each drum and a composite sample of a 1120 drums was made. Additionally, grab samples from several of the drums were taken to check the consistency of the liquids from drum to drum. One of the difficulties in analyzing the COALITE is related to its water content and relatively wide boiling range, ca., 160 to about $1000 \mathrm{~F}$ (71-538C). We found it expedient to first dewater the sample using a rotavap apparatus and then performing the various whole $0 i 1$ and distillate fraction analyses on the dewatered COALITE.

Analytical distillation was accomplished in two steps: atmospheric distillation via the ASTM D-86 procedure followed by vacuum distillation of the atmospheric bottoms using the $D-1160$ procedure. The consolidated distillation curve for the composite sample is shown on Figure 3.1-1. Figure 3.1-2 shows the quality comparison of the MCG-based COALITE liquids with that of conventional COED pyrolys is (2) oils.

In order to assess the amenability of COALITE distillates to hydroconversion to HEDr materials, it was determined that analytical characterization data on narrow boiling distillate fractions would be of value in formulating a hydroconversion test matrix. One objective of this analytical study was the determination of whether or not there was a sharp break point in cyclic HEDF precursor content with distillate boiling point. The COALITE composite was fractionated in laboratory true boiling point distillation apparatus to recover 16 successive distillate fractions spanning the range of 300-650F (148-343C). The analyses of the individual fractions are shown in Table 3.1-1. Figure 3.1-3 shows the yield curve vs. the volumetric average boiling point (VABP) of the respective distillate fractions. The VABP parameter has also been used as the irdependent correlating variable in analyzing distillate properties as a function of boiling range.

A heart cut, i.e., 200-550F (93-288C), was al so subjected to G.C./M.S. analysis using an SP-1000 column. The sample speciation, as provided by Professor Robert Baldwin of the Colorado School of Mines, is shown on Table 3.1-2. 

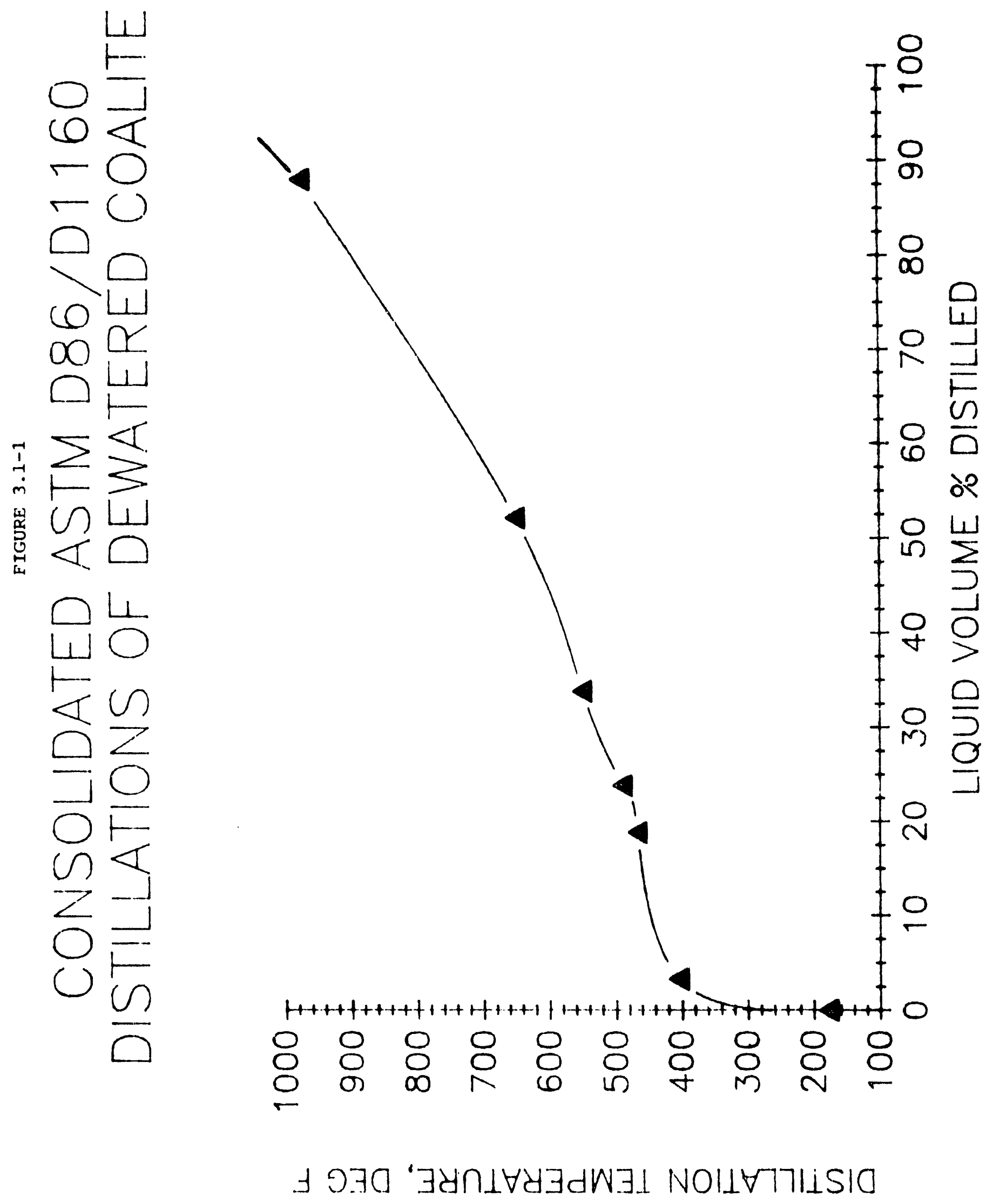


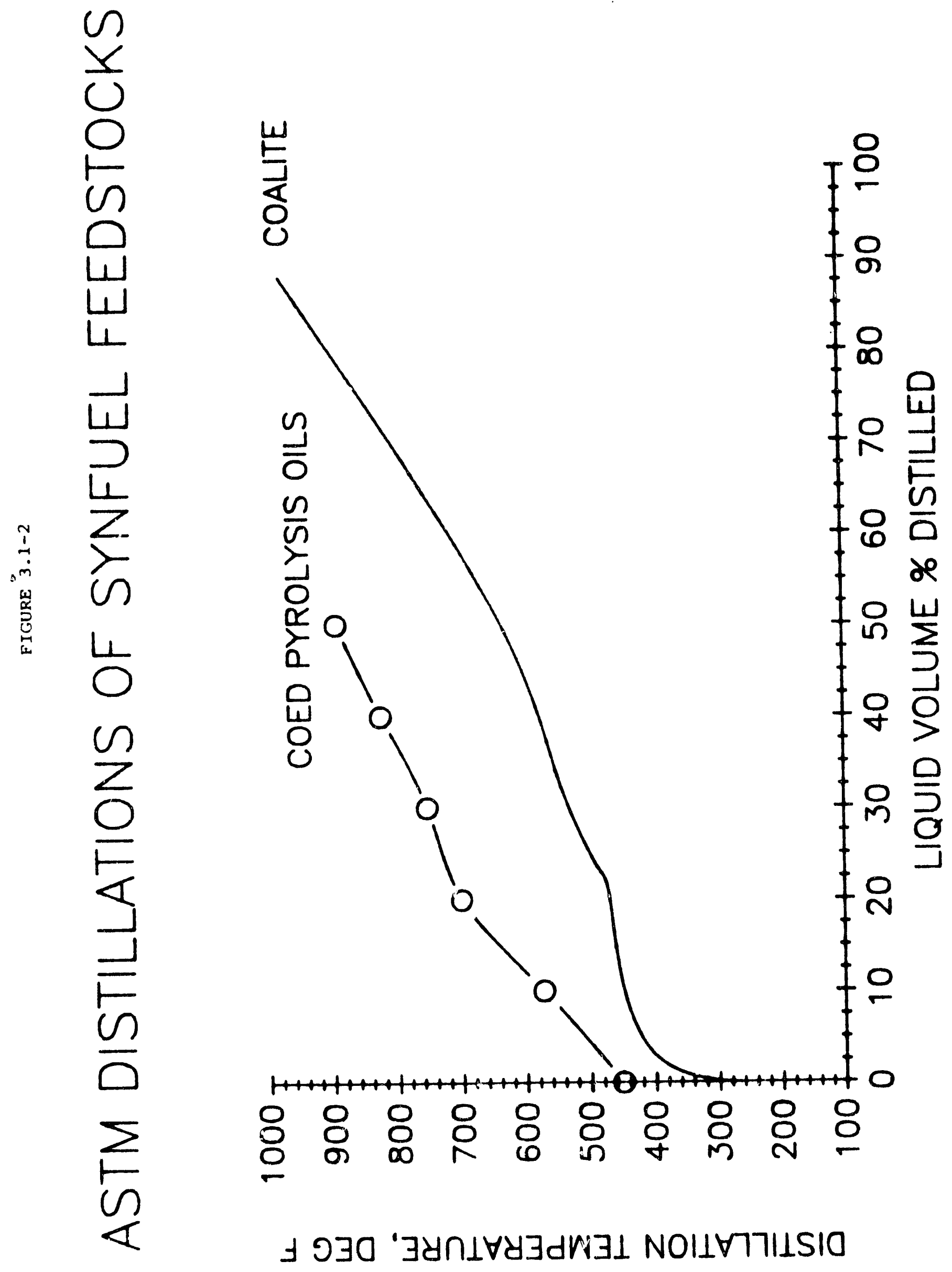




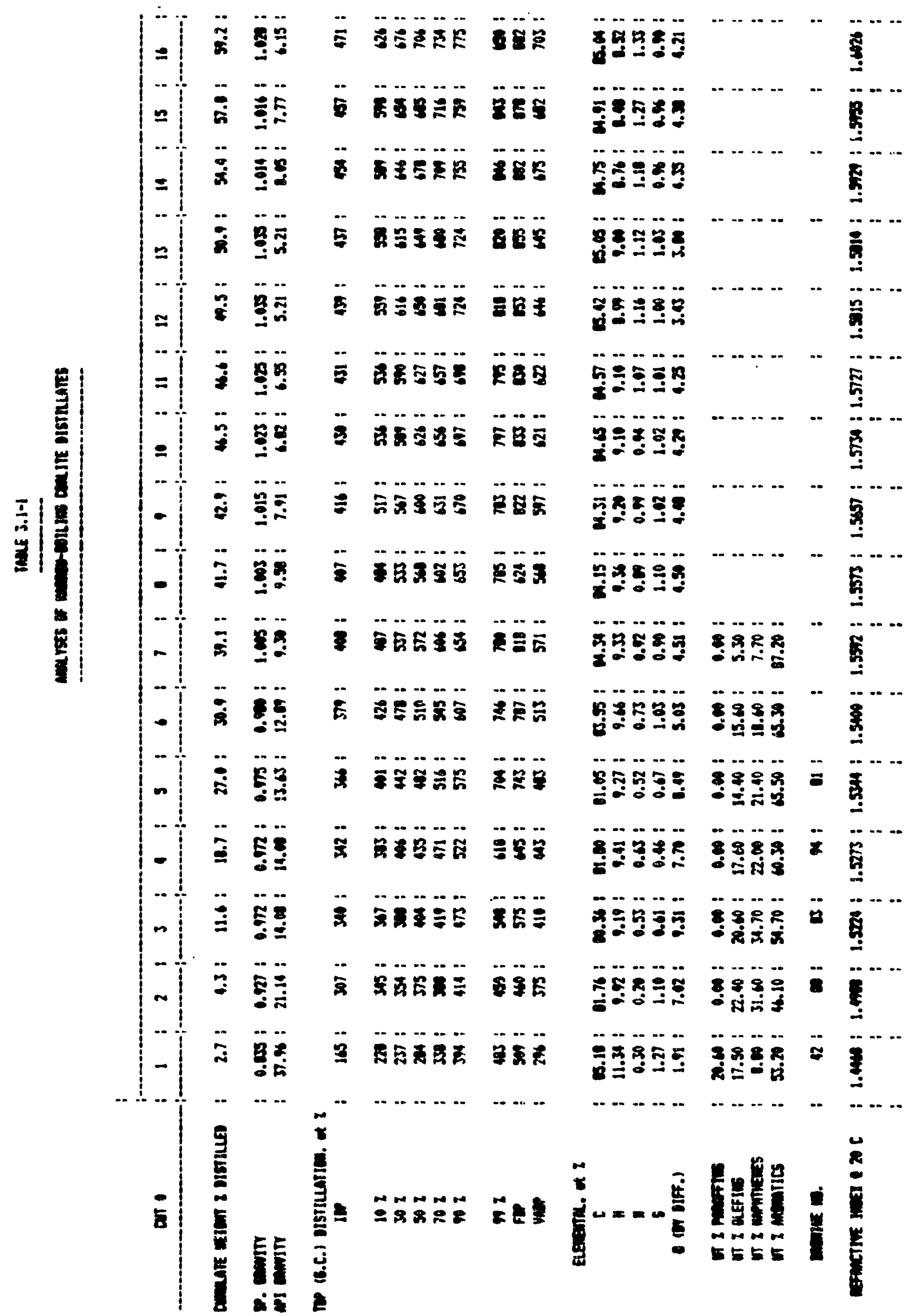




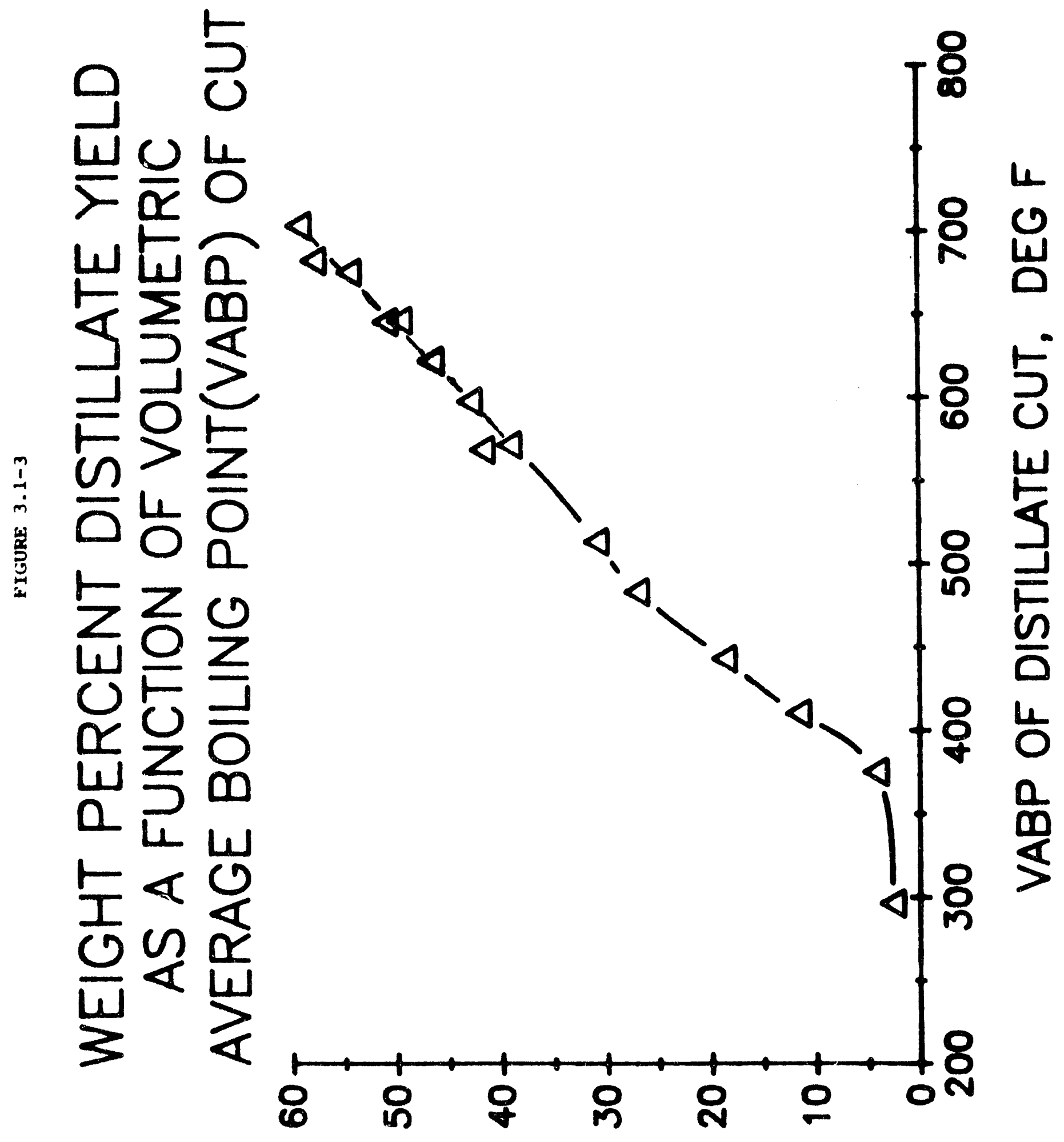

037רוSIO INJJYJd LHOIJM 
DOMLITE AIO DISTJLLATE (200-590 F)

usims sp-1000 callum

NT IIK

2.071

2.215

2.287

2.387

2.491

2.579

2.672

2.742

2.790

2.901

3.135

3.237

3.356

3.633

3.772

3.862

3.939

4.120

0.228

4.296

4.469

4.716

4.001

5.094

3.246

5.357

5.459

5.559

5.755

3.119

5.995

6.062

6.214

6.485

6.539

6.724

6.851

6.903

7.000

7.167

7.256

7.372

7.560

7.644

7.723

1.256

7.907

0.090

8.178

0.251

0.305

0.393

MEAT

conpony men

0.11 Deraftin or iscouraffin

0.14 moptane

0.06

0.14

0.13

0.22

0.46

0.07

0.10

0.36

0.05

0.21

0.16

0.69

0.33

0.11

0.14

0.05

0.15

0.60

0.00

0.10

0.55

0.07

0.03

0.02

0.30

0.60

0.03

0.10

0.03

0.11

1.20

0.07

0.17

0.45

0.27

0.24

0.52

0.09

0.20

0.10

0.63

0.14

0.15

0.23

0.11

0.10

0.21

0.10

0.30

omaffin or iscoaraftín

curaffin or iscopatfin

axteme

S-athyl-2-twenencene

Daraftin or iceparaffin

peratfin or iseparattin

exoffin or iseperatfin

monene

peraftin or issouratfin

ouratfin or iseparattin

oeroffin or iscoaralfin

morattin or iseparaffin

decane

araftin or isogaratfin

butyl ester of acetic cid

peratfin or iscperaftion

peratfin or isoparaffin

1,3,5-evelenceptateiene

meraffin or iscoaralfio

Derattin or iseparatfin

madecane

porattin or isoperaftin

peroffin or iscanastin

bif 91

bis 91

dienthyl cenzene

ceraffin er iseparaffin

ouratfin or isoparattin

peraftin or isoparotfin

oeroffin or isoparaftin

dodecane

bif 11

peraffin or ieparaffin

ethyl methyl benzene

1 - bodecene

1-enthyl-trikerene

triastivyl cenzeme

eseaffin or iscosatfin

othyl enthyl cenzese

coratfin or iseparaftin

ethyl esthyl benseme

tridecene

veraftion or iscopraffia

cothyl propl benzome

paraftin or iseparaffio

peroffin or iseparation

ethyl diesthyl benzewe

coraffin er iscoaraffin

C13 isceraftin

trisethyl bentone 


\begin{tabular}{|c|c|c|}
\hline 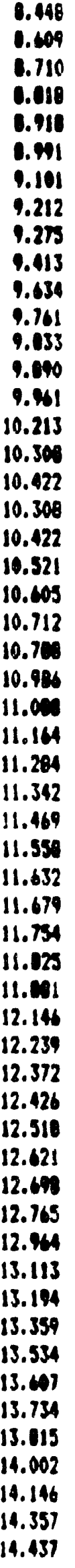 & 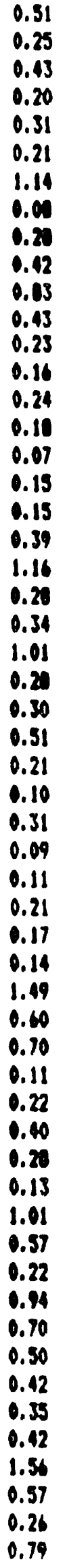 & 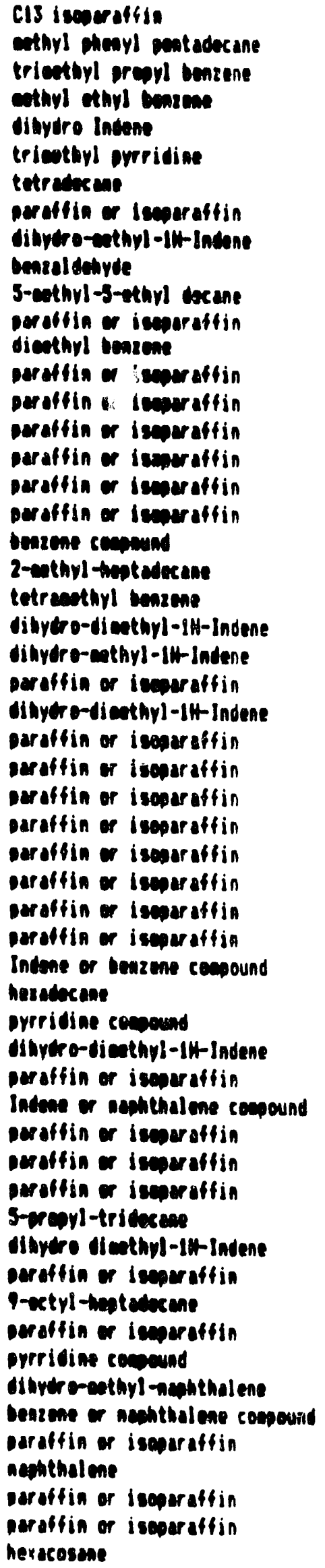 \\
\hline
\end{tabular}




\begin{tabular}{|c|c|c|}
\hline 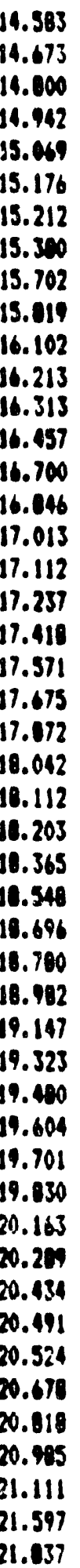 & 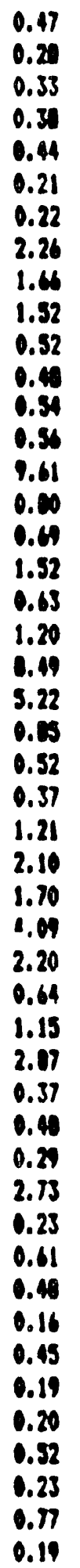 & 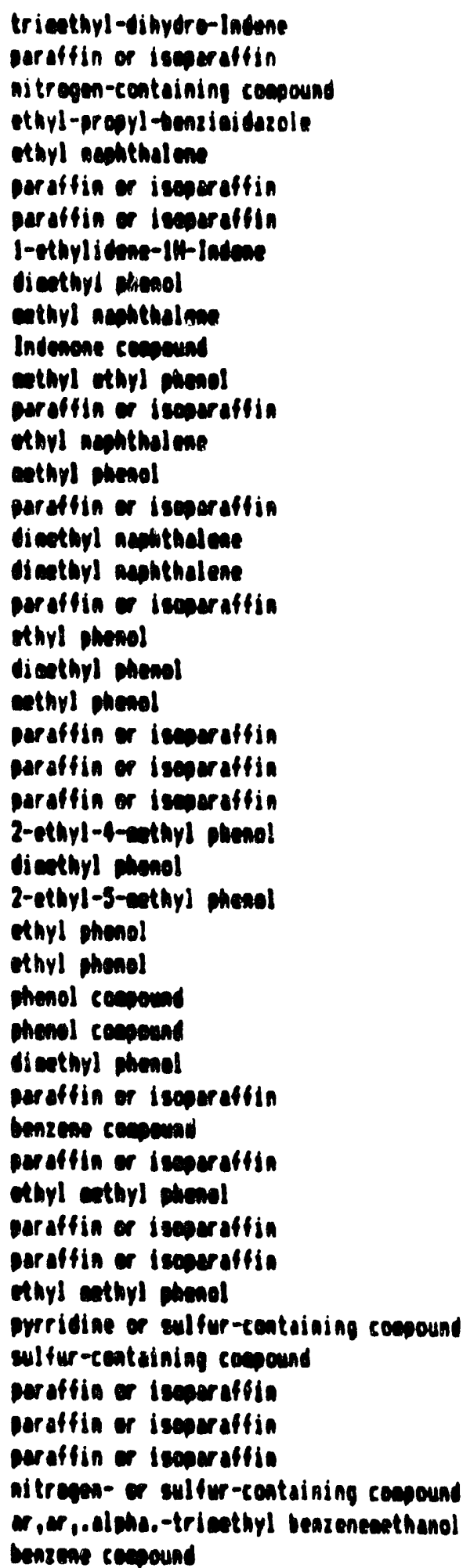 \\
\hline
\end{tabular}


Figure 3.1-4 shows the $H / C$ atomic ratio of the COALITE distillates as a function of VABP. As expected, the $H / C$ ratio decreases as VABP increases. Also shown on the figure is the $H / C$ ratios required for the HEDF product. The $\mathrm{H} / \mathrm{C}$ atomic ratio of the raw COALITE distillates has to be improved by approximately $40 \%$.

Figure 3.1-5 shows the API Gravity of the COALITE distillates as a function of VABP. The API of the finished HEDF product should be about 20-40 degrees API higher than that of the raw COALITE 300-650F (148-343C) distillate.

Figures 3.1-6, 7, and 8 show the nitrogen, oxygen and sulfur contents of the COALITE distillates as a function of VABP. Nitrogen content increases linearly with VABP. Oxygen content, as determined by difference, appears to decrease almost linearly with VABP. Sulfur content shows an unusual minima at about 450F (232C) average boiling point and then lines out at a value of about $0.9-1.0$ wt percent at higher VABP.

PONA analysis based on the F.I.A./Refractive Index method was used as a measure of hydrocarbon types. The resultant data are presented on Figure 3.1-9. It is to be cautioned that the method may not be accurate for non-petroleum, synfuel-derived distillates such as COALITE. The general trend indicates a continual increase in aromaticity as VABP increases.

Proton NMR spectroscopy was used as an additional analytical tool to assess the hydrogen and carbon distributions in COALITE distillates. Table 3.1-3 shows the NMR parameters for a 390-650F (198-343C) boiling distillate. Figures 3.1-10, 11 , and 12 show the NMR hydrogen distributions, carbon distributions and $\mathrm{H} / \mathrm{C}$ atomic ratios respectively as a function of VABP.

Bromine No., which is a measure of carbon-carbon double bond content, for four lighter COALITE distillates is plotted VS VABP in Figure 3.1-13. There is little effect of VABP on Bromine No. over the range evaluated.

Refractive Index $(\varrho 20 C)$ is a rapid analytical tool and a good measure of distillate quality. Figure 3.1-14 shows the effect of VABP on distillate Refractive Index. Refractive Index can also be used as an independent correlating variable similar to that of the VABP parameter. Figures $3.1-15,16,17$, and 18 show the dependency of several distillate properties as a function of the Refractive Index. Also shown on the latter four graphs are data published by METC (3) for a variety of full-range coal liquids and shale oils. While the LCI and METC correlations are not compeletely congruent, the Refractive Index parameter does show to be a widely usable correlating tool. 


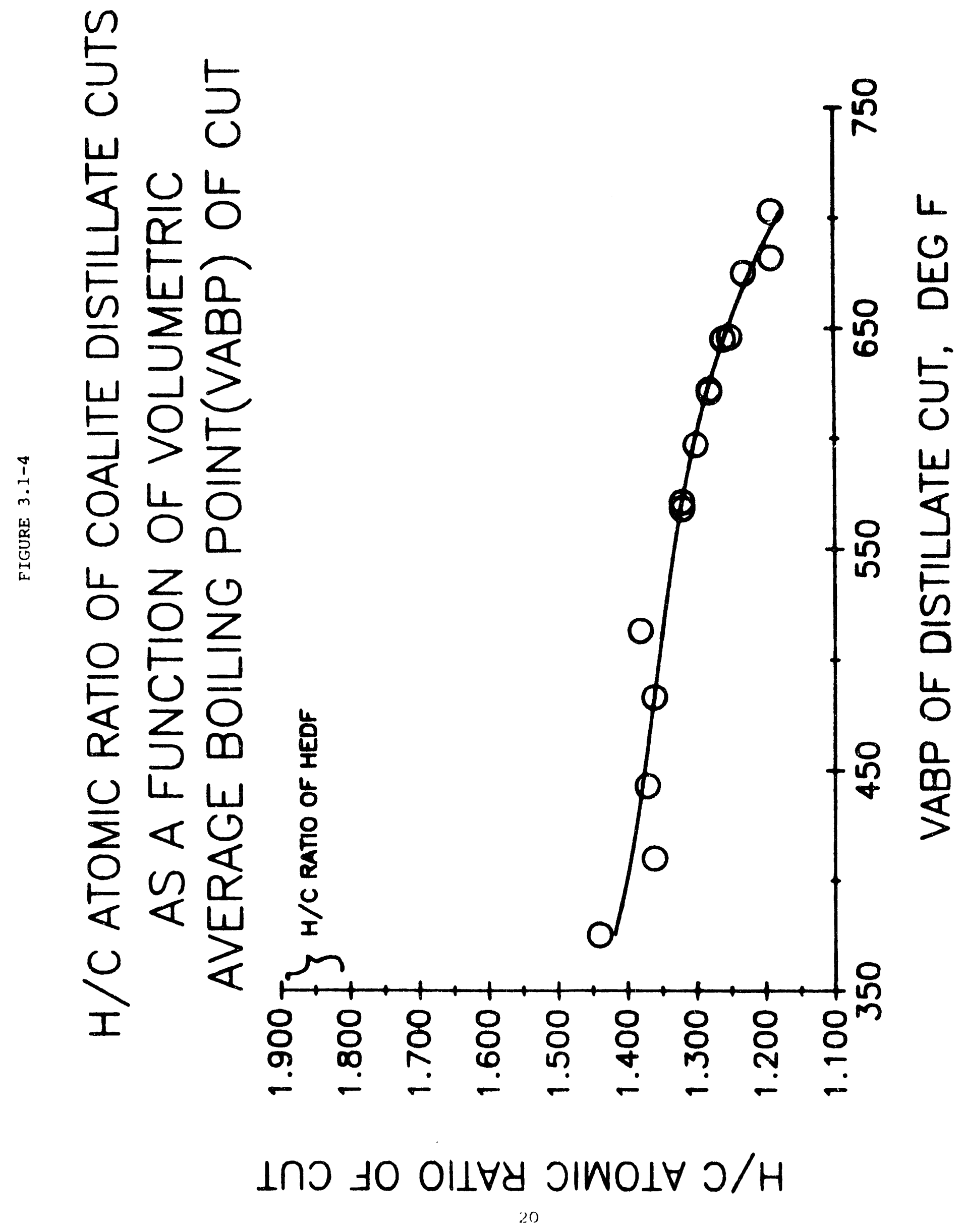



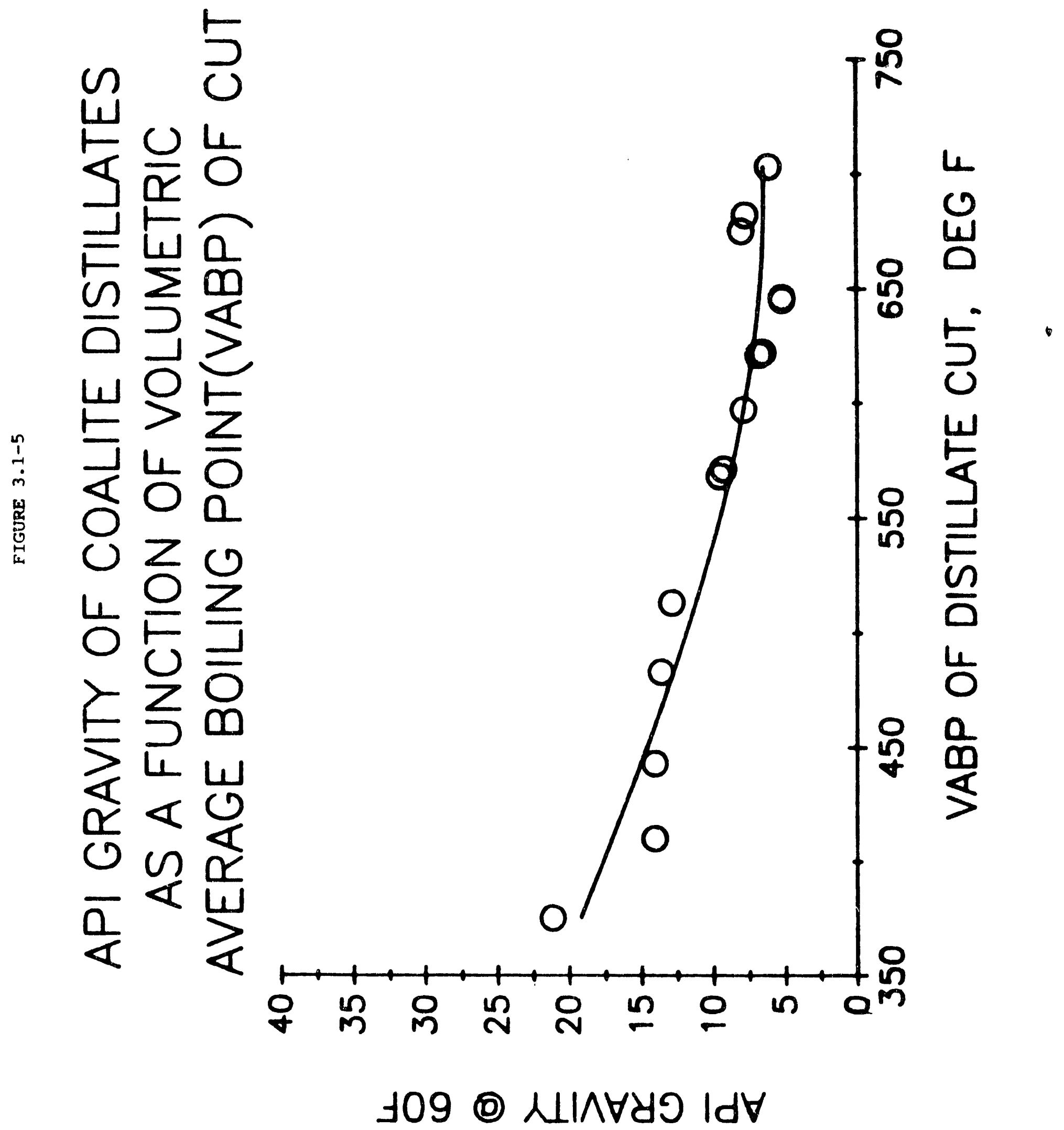


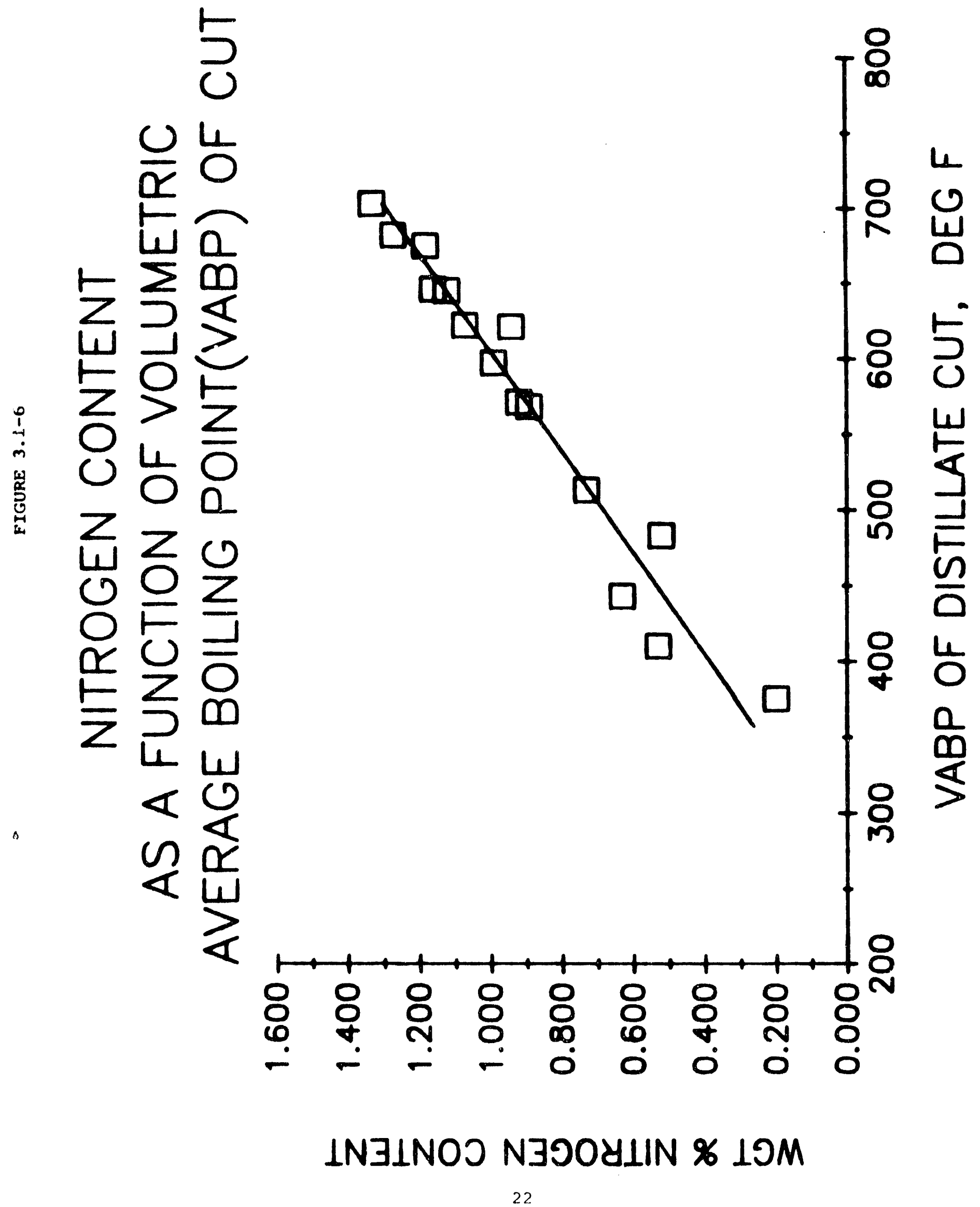




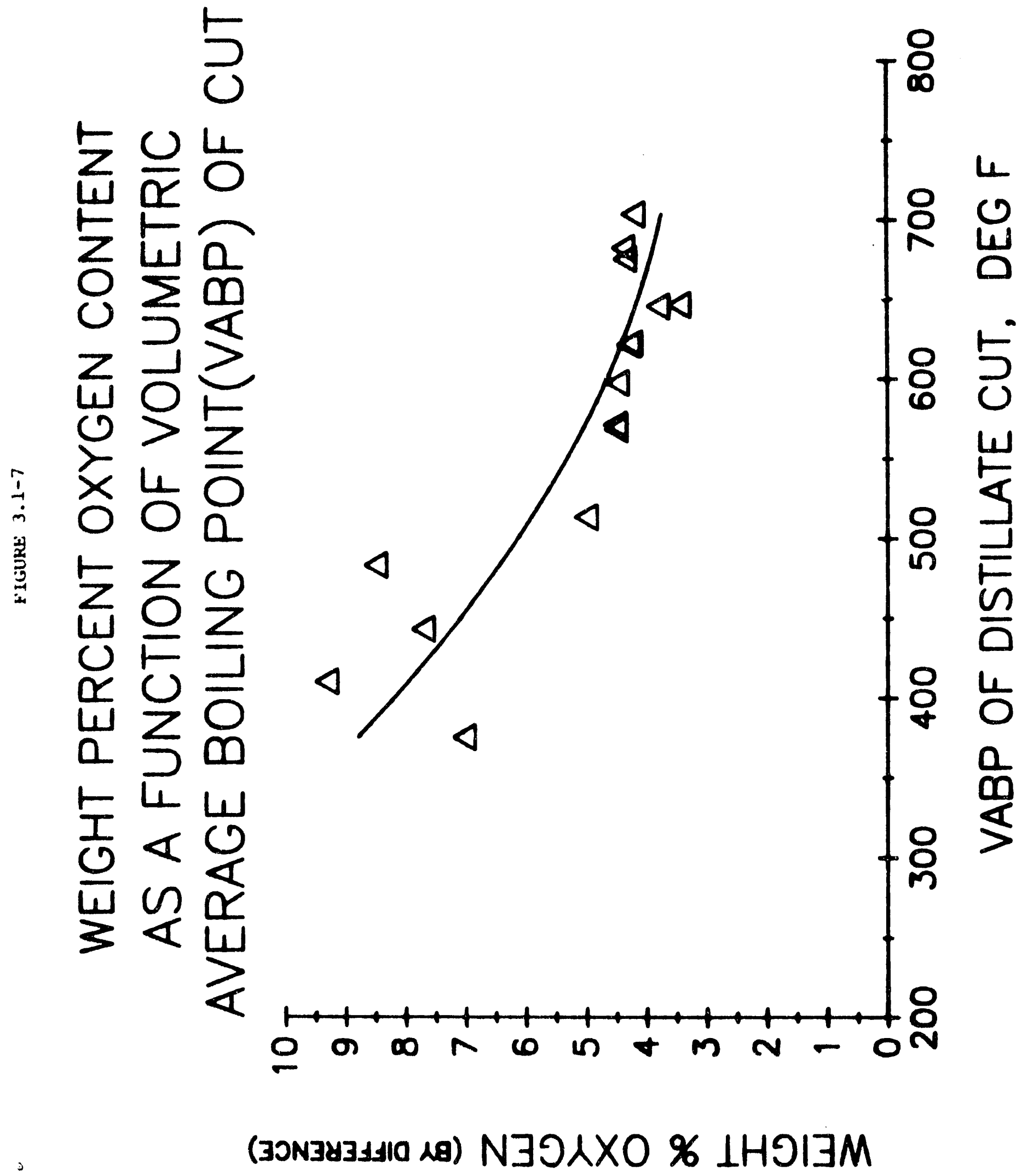




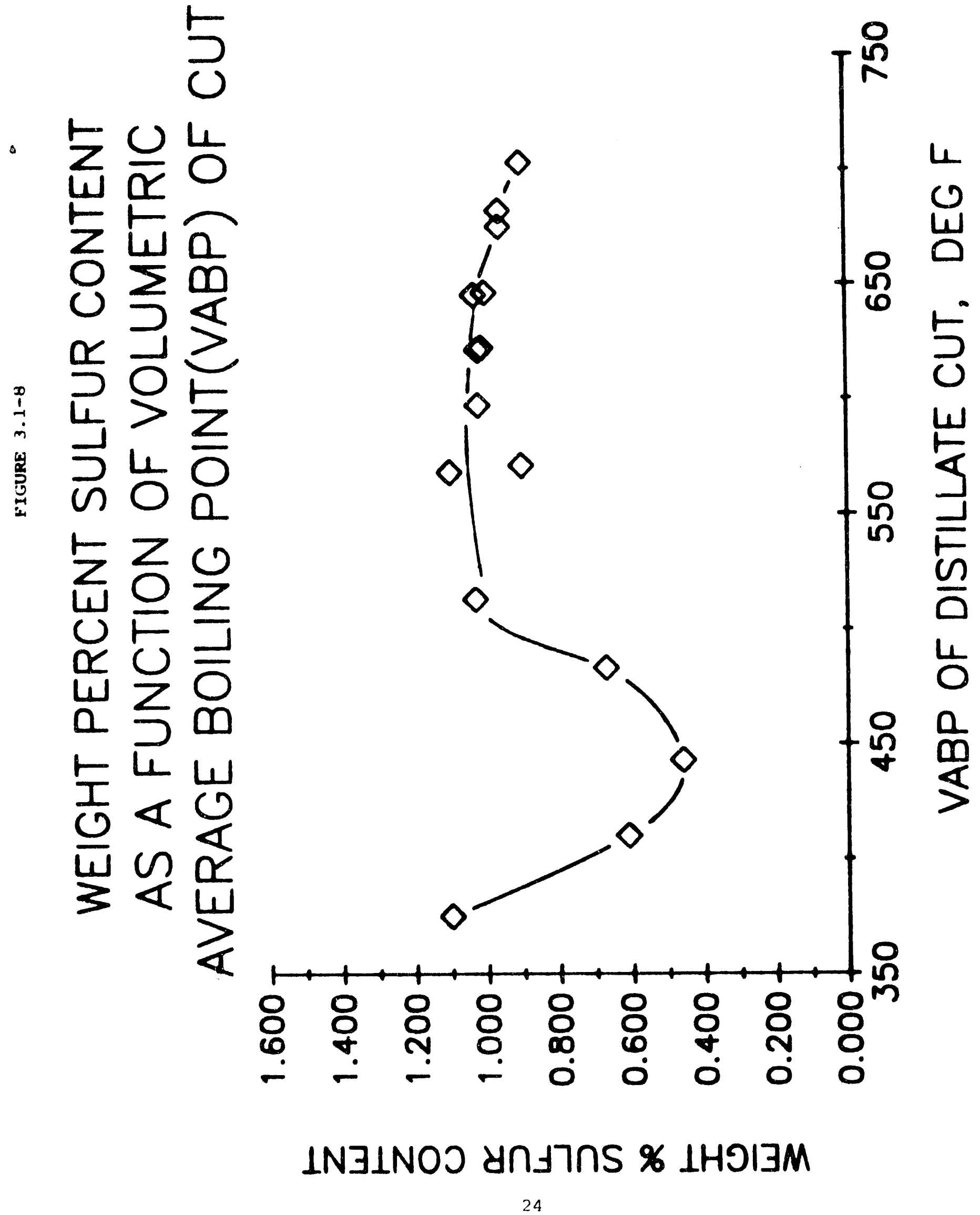




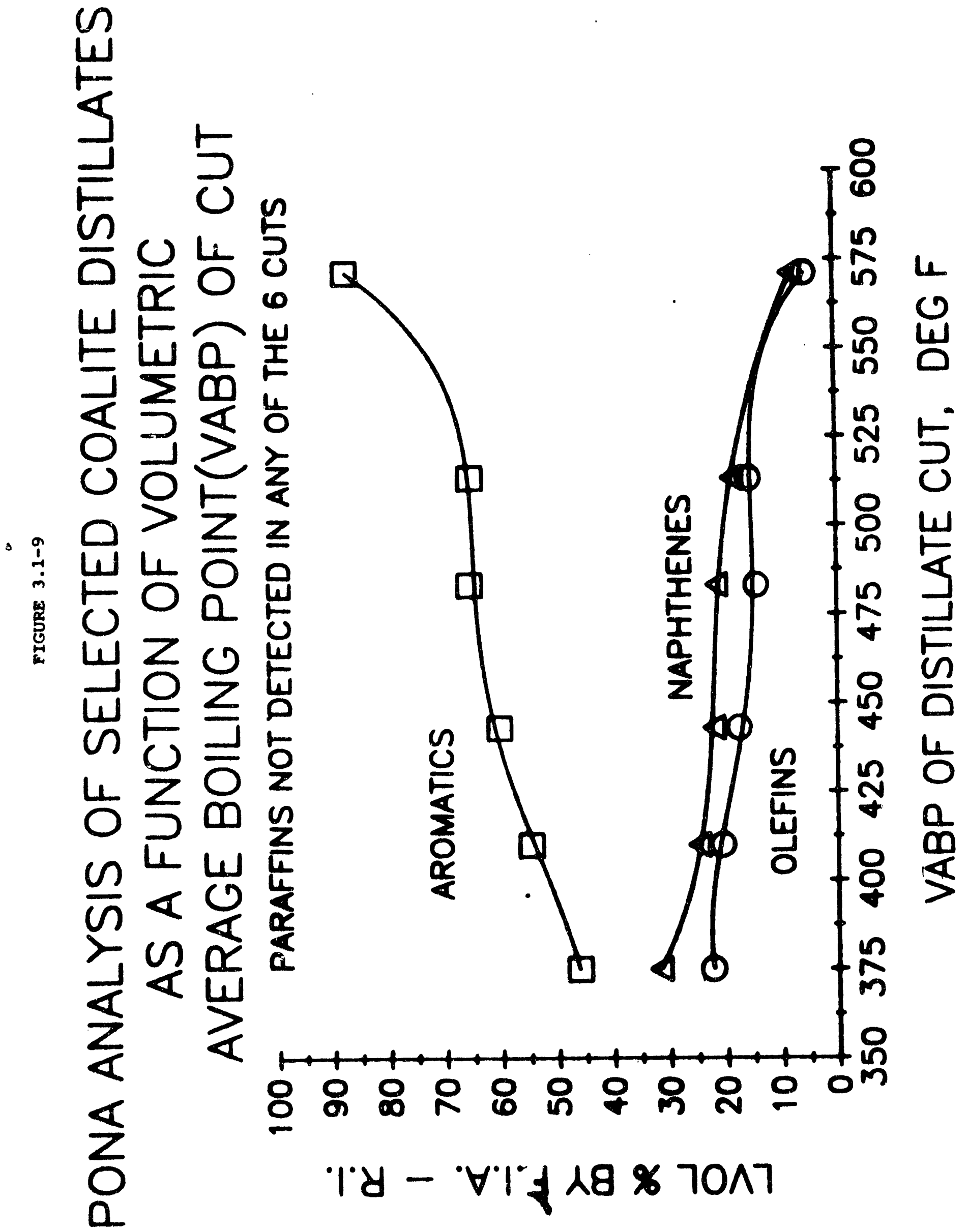


TABLE 3.1-3

MUR SPECTROSCOPY OF $390-650^{\circ} \mathrm{F}$ COALITE

HYDROGEN DISTRIBUTION

\section{ELEMENTAL ANALYSIS \%}

C

(H/C) ELEMENTAL ANALYSIS

(H/C) NMR

H AROM/C AROM

H SAT/C SAT.

H A POLY,\%

H A MONO

HF

$\mathrm{HAl}$

$H A 2$

H B1

H B2

H G

TOTAL H

H AROM \%

H SAT\%
9.26

84.02

1.31

1.34

0.58

2.26

12.8

11.3

0

7.3

23.7

9.4

23.5

12.0

100.0

24.1

75.9

\section{CARBON DISTRIBUTION}

C A POLY

C A MONO

C F

C Al

C A2

C B1

$C B 2$

C G

32.8

22.4

0

10.5

8.4

15.7

5.3

TOTAL C\% $\quad 100.0$

C AROM \% 55.2

C SAT \% $\quad 44.8$

C A SUB $\% \quad 27.9$

C A UNS \% $\quad 58.4$

C A INT \% 13.7

C A PER \% 86.3

C A INT \% 13.7

C NAPHT $\% \quad 18.8$

f AROM $\quad 0.552$

\% AS

CPER/CINT

B. 1 .

C/H SAT W

n CHAIN
32.4

6.29

0.37

5.27

2.5 


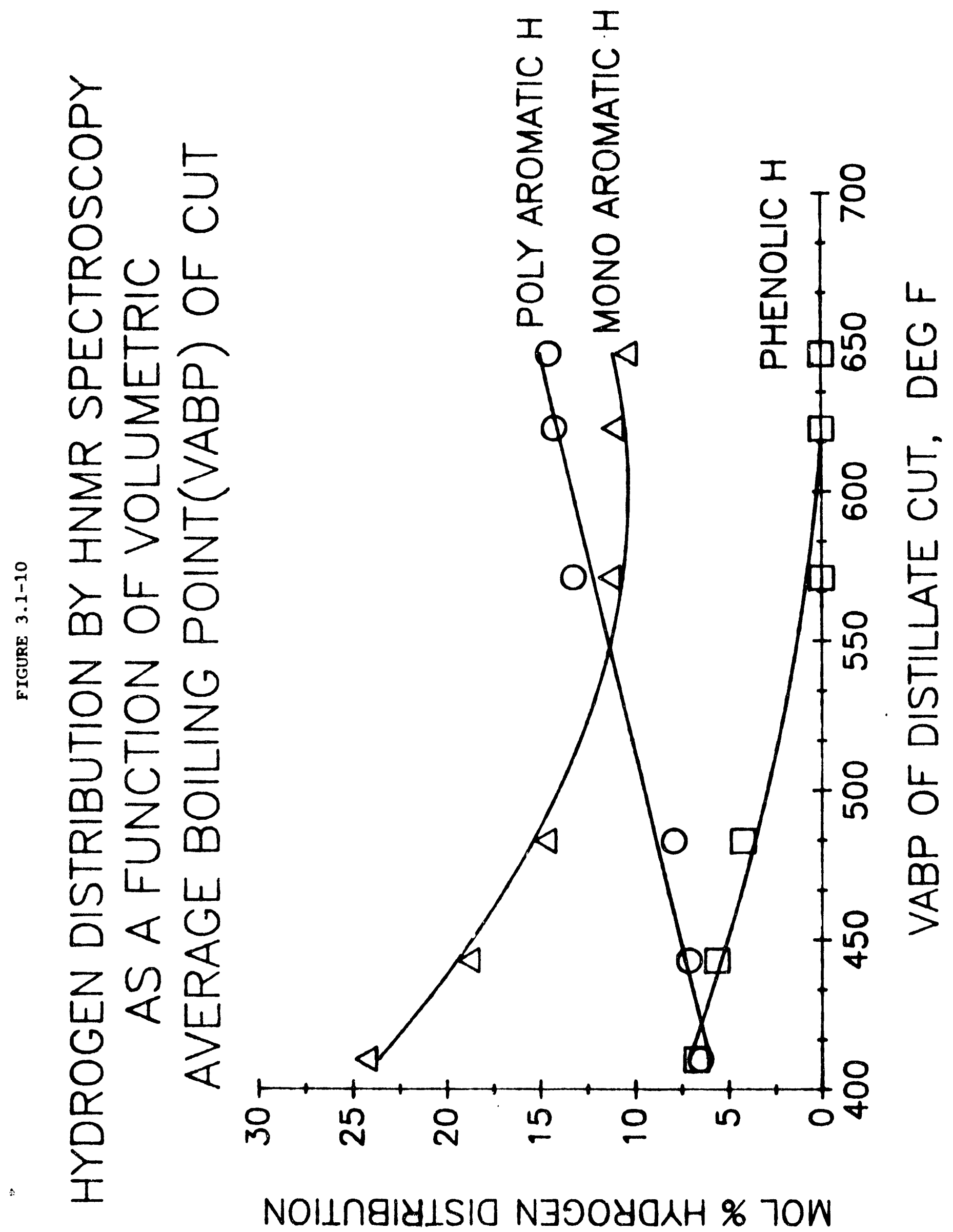




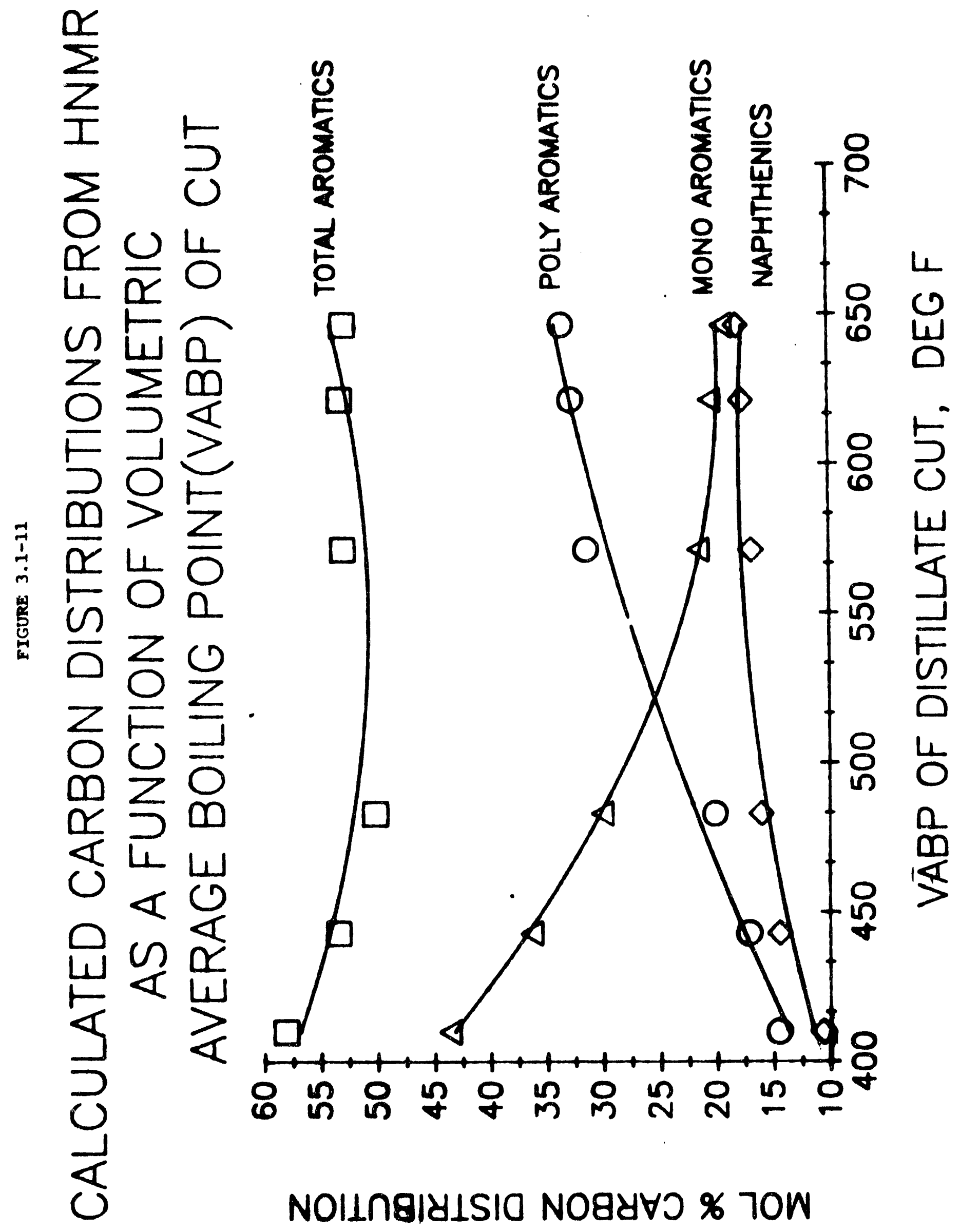




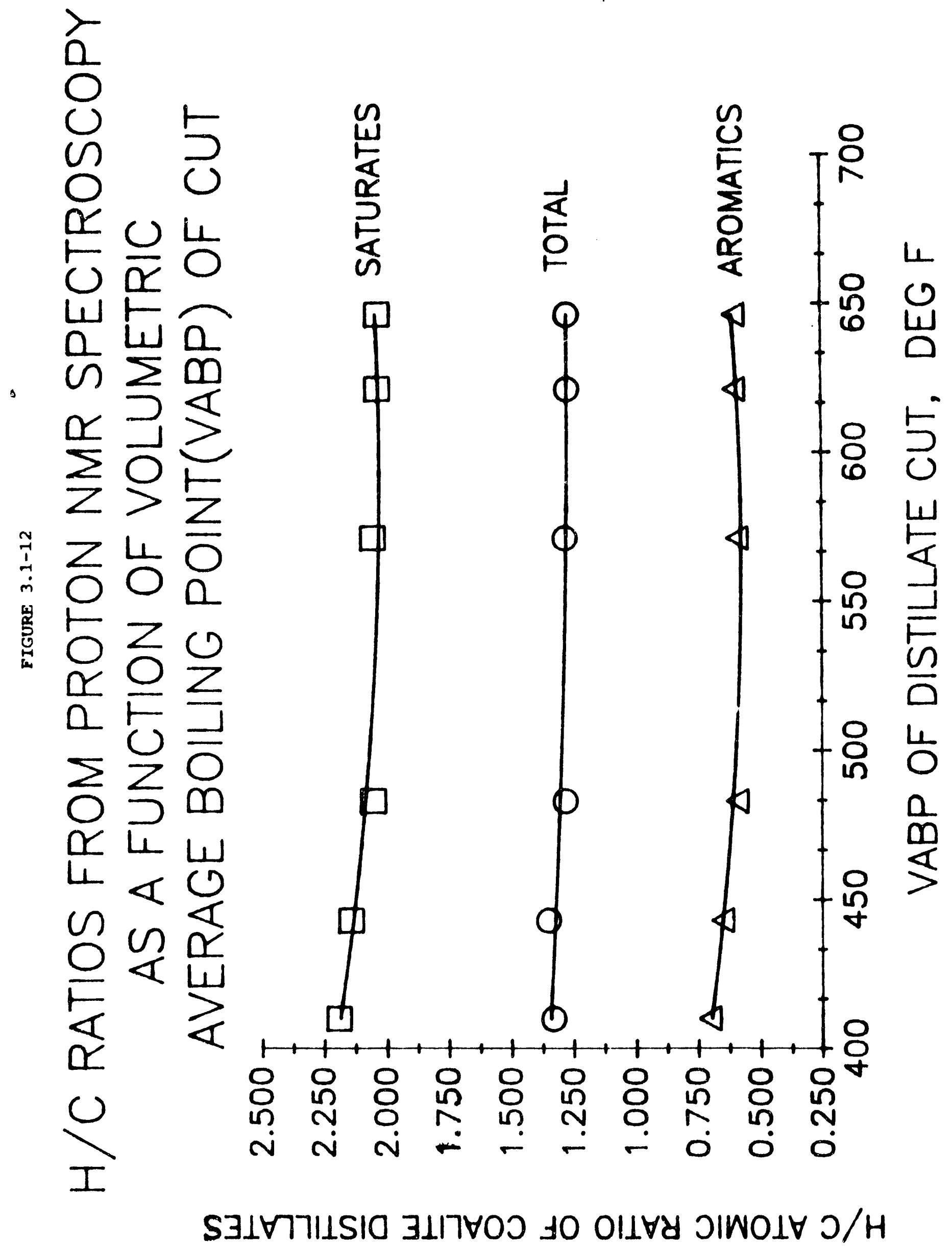




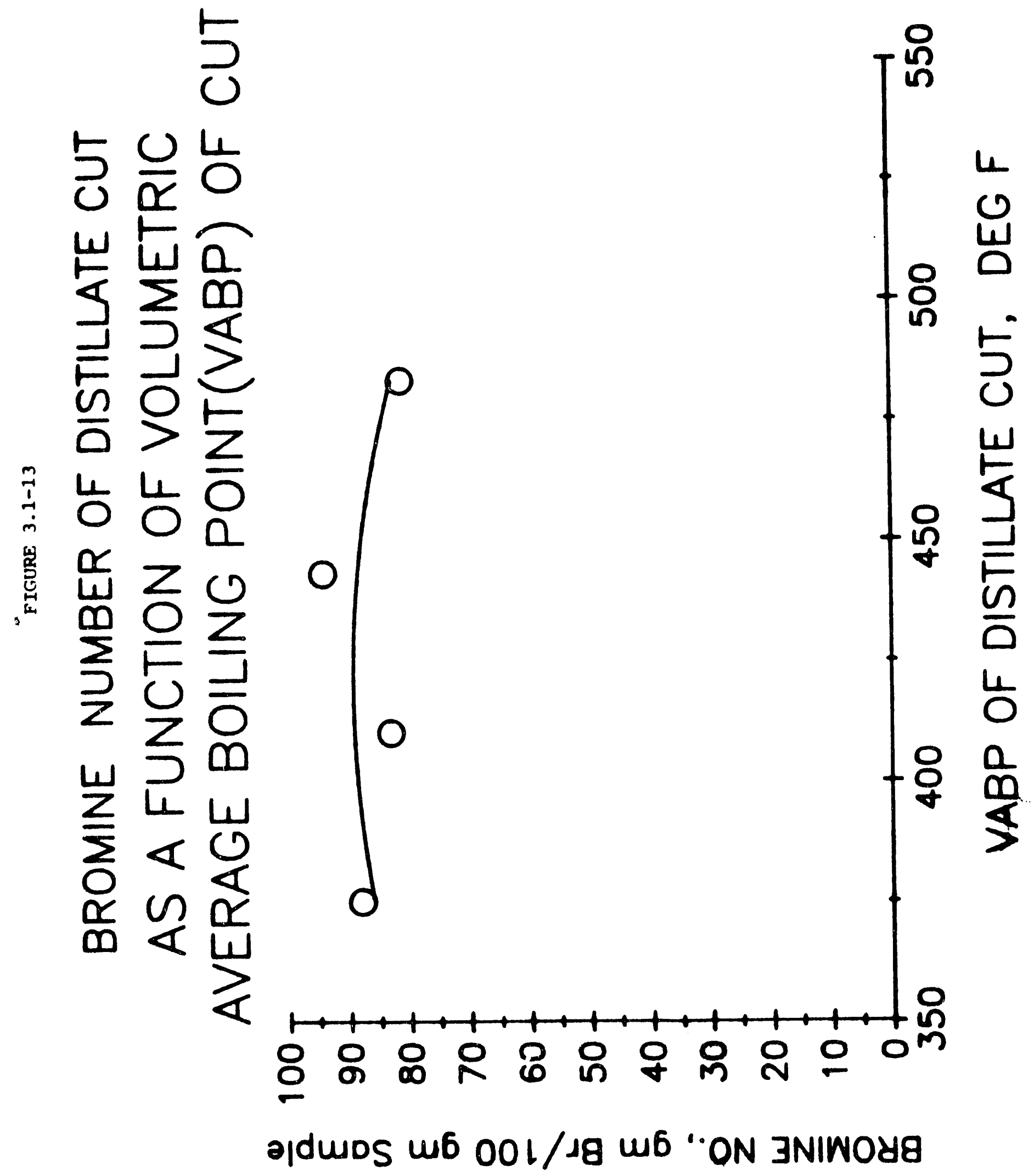




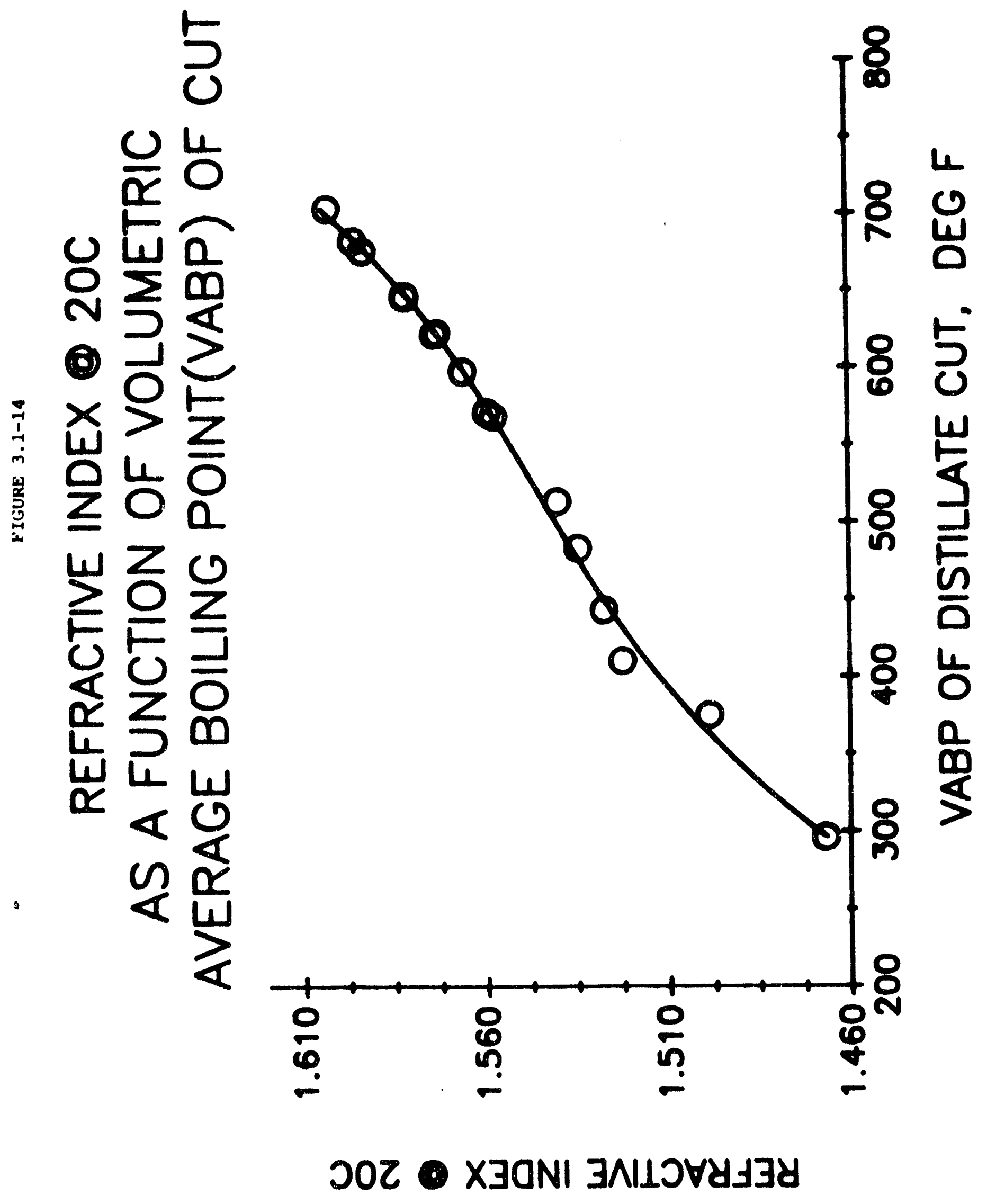




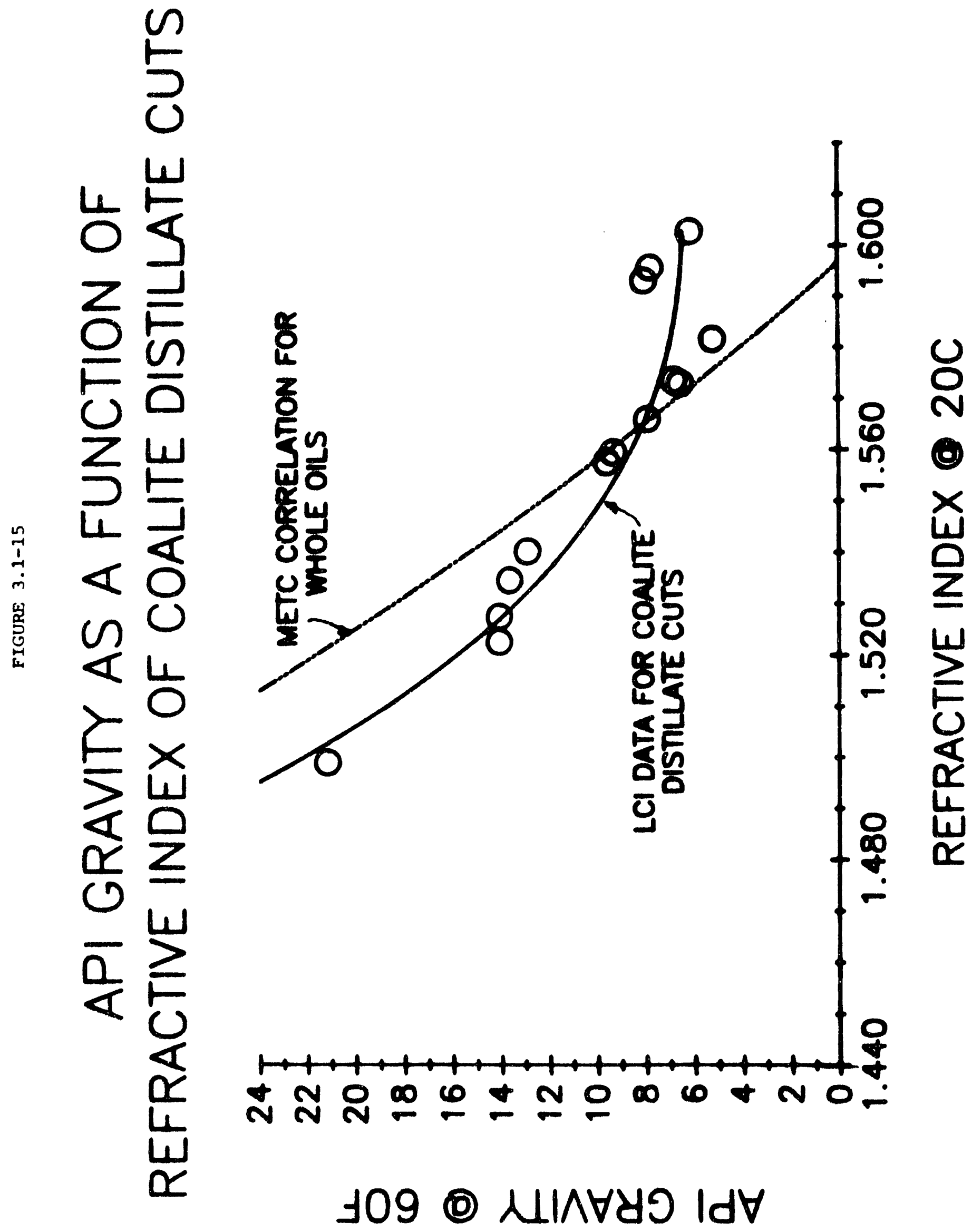




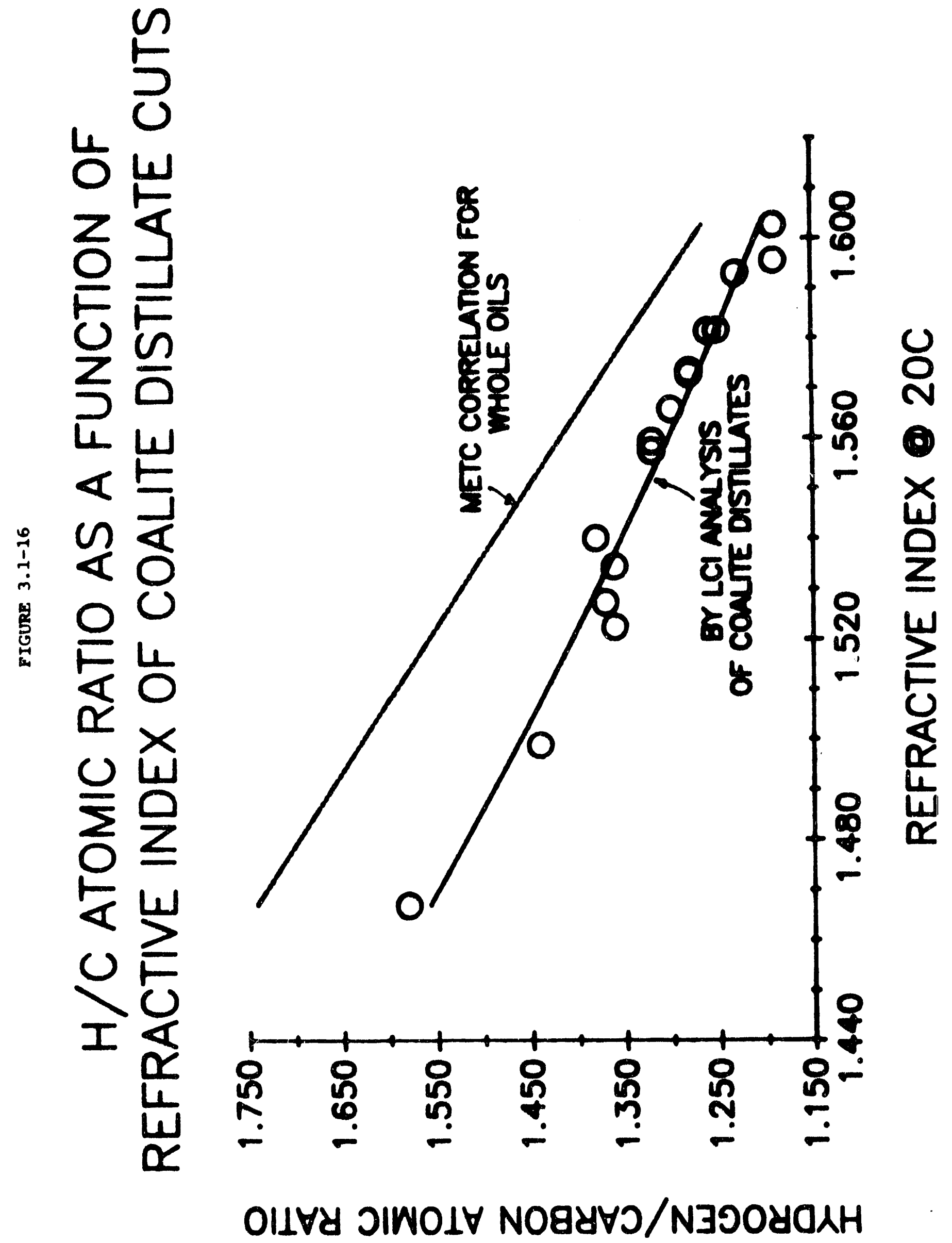




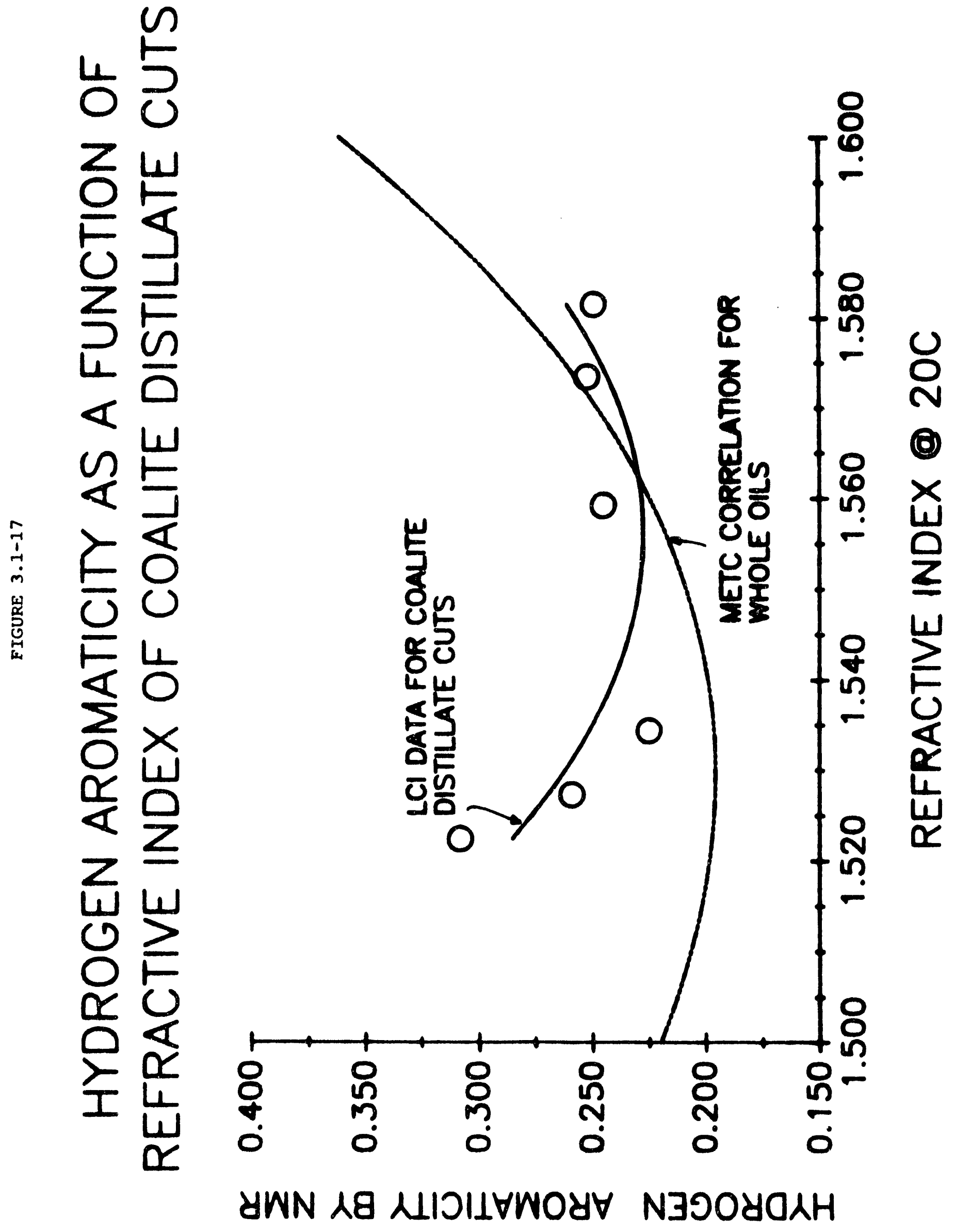




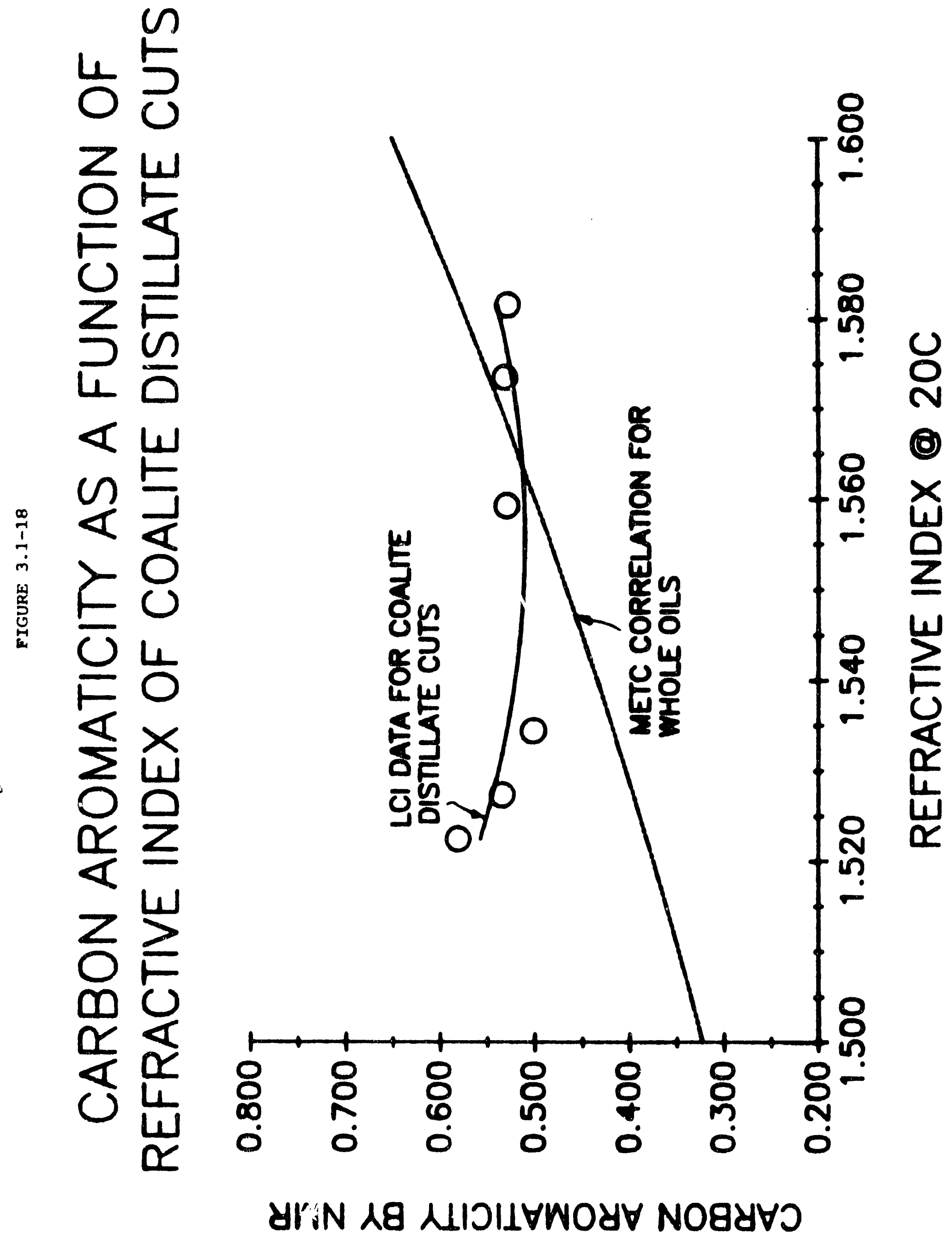




\subsection{PILOT PLANT SAMPLE PREPARATION OPERATIONS}

\subsection{Overview}

While sample preparation for the purpose of end user assessment is a very important component of process development. The end user assessment can provide good feedback to the process developer on the properties of the test fuels under static and dynamic engine test evaluations. However, the structure of this project allowed for only a single interface between the process developer and the end user of the HEDF test fuel and this interface will occur after the termination of the project. Accordingly, the decision on what fuel samples of the many options available to the process developer is a critical one. In selecting processing conditions, it was necessary to consider the tradeoffs in ultimate HEDF yield with fuel cut points, the latter having great effects on the energy density and thermal stability properties of the candidate HEDF fuels. It was also necessary to consider the severities of the various hydroprocessing steps and their impacts on capital and operating costs. Finally, good judgment had to be applied in selection of screening conditions since the project, and especially the Task 5 pilot plant sample preparation program, had definitive cost and schedule limitations.

The original work statement called for production of test samples from both the COALITE MCG liquids as well as from UNOCAL Process-derived Colorado shale oils. Since the Colorado shale oils were shown during the Task 3 screening studies to be less responsive to hydroprocessing with regards to achieving $130,000+$ Btu/gal energy densities, the work statement was modified to concentrate on the COALITE liquids and to produce two different quality HEDF test fuel sampies based on COALITE processing. The particular processing methodology selected for the sample preparation efforts was based on a target of optimizing the volumetric energy density-thermal stability relationships for the HEDF fraction. The processing steps consisted of:

- Fractionating the raw full-range COALITE to generate a 575F+ atmospheric resid fraction;

- LC-Fining of the 575F+ COALITE to hydrocrack some of the vac resid components as well as to impart part of the hydrogen uptake requirements in a backmixed, near isothermal reaction system;

- Flash vaporizing the full-range LC-Finates to remover the unconverted $900 \mathrm{~F}+\mathrm{vac}$ resid;

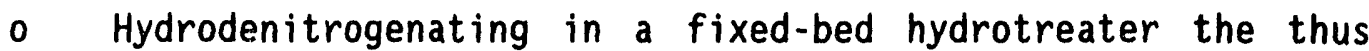
prepared IBP-900F LC-Finate gas oils using a NiMo catalyst selective to deep denitrogenation removal; 
- Selectively hydrocracking the hydrodenitrogenated LC-Finate gas oils using a proprietary zeolitic-based hydrocracking catalyst in a fixed-bed hydrotreater at two operating severities;

- Fractionating the hydrocrackate products to recover the nominal 280-580F HEDF precursors;

o Clay treating the 280-580F materials over bentonite to remove trace polar impurities; and

o Treating the HEDF test fuels with anti-oxidant and corrosion inhibitor.

\subsection{LC-Fining ${ }^{\text {Sm }}$ Operations}

The first step in the overall sequence to produce finished HEDF test fuel from the raw COALITE feed is to hydroprocess the atmospheric resid cut via expanded-bed LC-Fining. The throughput to the LC-Fining unit was specified to insure that there would be a minimum quantity of HEDF precursors in the LC-Finate products necessary for the achievement of at least 25-gal of HEDF test fuels. Run 6LCF-14 was carried out using Shell 324M NiMo catalyst recovered from a prior campaign in the LC-Fining pilot unit made during Subtask 3.2 to recover LC-Finates for the screening studies. The 6LCF-14 feed was derived from the $575 \mathrm{~F}+$ atmospheric resid fraction recovered during the batch fractionation (in an 8-in batch fractionation unit) of the raw COALITE material.

The LC-Fining unit was successfully pressure tested at 2500 psig hydrogen pressure and commissioned with a 350-575F raw COALITE distillate until the catalyst bed temperature was 500F. At this point, the distillate feed was removed and the 575F+ resid was introduced which increasing the heat inputs until the desired catalyst bed temperature was achieved.

The run proceeded for four days without any major operating problems and a total of 105 gallons of LC-Finate were recovered. The reactor operating conditions were 2000 psig operating pressure, $773 \mathrm{~F}$ average catalyst bed temperature, $6000 \mathrm{scfb}$ treat gas rate and 1.5 LHSV per each of the two catalyst beds.

As indicated in Table 4.2-1, the conditions for run 6LCF-14 were more severe than those of the prior Subtask 3.2 screening test of run 6lcf-11. The bed temperatures were about $9 \mathrm{~F}$ higher and space velocity per bed was about $0.1 \mathrm{hr}^{-1}$ lower. The incremental increase in severity was an attempt to match the posiable catalyst activity loss attributable to the use of the spent catalyst. The LC-Finate product characteristics did indicate that the catalytic activity was less than that of run $6 L C F-11$ based on the HDS and HDN removal efficiencies. However, thermal conversion activity was greater as indicated by the $575 \mathrm{~F}+$ conversion. Chemical hydrogen consumptions were approximately equivalent for both tests (2700-2800 scfb). 


\begin{tabular}{|c|c|c|}
\hline \multicolumn{3}{|c|}{ 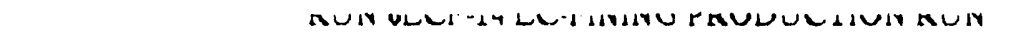 } \\
\hline 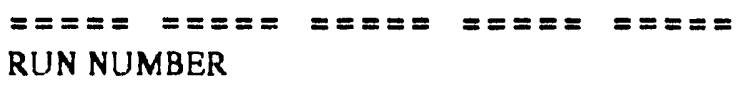 & $\begin{array}{l}==== \\
6 \mathrm{LCP}-11\end{array}$ & $\begin{array}{l}x=== \\
6 \mathrm{LCP}-14\end{array}$ \\
\hline PERIOD NUMBER & 3 & \\
\hline -................. & $-\cdots---$ & \\
\hline DATE (1990) & $3 / 31$ & $12 / 12$ \\
\hline AVG. CATALYST TEMP. (1st BED) & 759 & 774 \\
\hline AVG. CATALYST TEMP. (2nd BED) & 769 & 772 \\
\hline TOTAL PRESSURE, PSIG & 2000 & 2000 \\
\hline LHSV PER BED, HOURS-1 & 1.63 & 1.49 \\
\hline SHELL 324M CATALYST AGE, BBL/LB & 0.17 & 0.272 \\
\hline TWO-STAGE WDSV, BBLRB/DAY & 0.071 & 0.064 \\
\hline TREAT GAS $(\mathrm{HZ})$, SCP/BBL & 5900 & 6000 \\
\hline CARBON BALANCE WT.\% RECOVERY & 101 & 99 \\
\hline OVERALL MAT.BAL, WT.\% RECOVERY & 100 & 100 \\
\hline \multicolumn{3}{|l|}{ PEED COALITE (S7SP +) PROPERTIES } \\
\hline API GRAVITY & -3.7 & -3.7 \\
\hline CARBON, WT.\% & 85.37 & 24.72 \\
\hline HYDROGEN, WT.\% & 8.01 & 7.86 \\
\hline SULPUR, ppm & 10200 & 9340 \\
\hline NITROGEN, ppm & 14100 & 8500 \\
\hline OXYGEN, WT.\% & 4.03 & 5.48 \\
\hline ASH, WT.\% & 0.16 & 0.16 \\
\hline $975 F+$ RESID, VOL.\% & 18 & 123 \\
\hline \multicolumn{3}{|l|}{ LC-FINATE LIGHT OIL PRODUCT PROPERTIES } \\
\hline API ORAVITY & 28.2 & 24.8 \\
\hline CARBON, WT. $\%$ & 87.82 & 88.33 \\
\hline HYDROGEN, WT.\% & 1205 & 11.52 \\
\hline SULFUR, ppm & 195 & 167 \\
\hline NITROGEN, ppm & 1118 & 1253 \\
\hline 575F + RESID, VOL.\% & 23 & 31 \\
\hline \multicolumn{3}{|l|}{ LC-FINATE HEAVY OIL PRODUCT PROPERTIES } \\
\hline API GRAVITY & 11.6 & 10.3 \\
\hline CARBON, WT.\% & 89.32 & 89.39 \\
\hline HYDROGEN, WT.\% & 10.24 & 9.99 \\
\hline SULFUR. ppm & 186 & 222 \\
\hline NITROGEN, ppm & 3121 & 3106 \\
\hline OXYGEN, WT.\% (DIFF.) & 0.11 & 0.29 \\
\hline ASH, WT.\% & 0.02 & 0.02 \\
\hline S75F + RESID, VOL.\% & 88.8 & 93.9 \\
\hline $975 F+$ RESID, VOL.\% & 9.0 & 9.8 \\
\hline \multicolumn{3}{|l|}{ PRODUCT YIELDS, WT.\% FEED } \\
\hline OPPGAS HXS & 1.07 & 0.97 \\
\hline OPFGAS NH3 + $\mathrm{H} 2 \mathrm{O}$ & 5.89 & 6.83 \\
\hline OFFGAS Cl & 0.69 & 0.26 \\
\hline OFFGAS C2 & 0.66 & 0.82 \\
\hline OPFGAS C3 & 0.70 & 0.86 \\
\hline OFFGAS C4 & 1.66 & 2.05 \\
\hline OFFGAS CS+ & 0.81 & 1.00 \\
\hline LIGHT OIL & 29.68 & 49.26 \\
\hline HEAVY OIL & 6230 & 41.02 \\
\hline TOTAL & 103.46 & 103.67 \\
\hline H2 CONSUMPTION, SCP/BBL & 2700 & 2800 \\
\hline DENITROGENATION, WT.\% & 84 & 78 \\
\hline DESULPURIZATION, WT. $\%$ & 98 & 98 \\
\hline VOL.\% $\% 75$ DEG. F + CONVERSION & 30 & 38 \\
\hline VOL.\% 975 DEC.F + CONVERSION & 65 & 64 \\
\hline
\end{tabular}


At the end of run 6LCF-14, the composited heavy oil fraction containing unconverted $975 \mathrm{~F}+$ COALITB was processed in the Equilibrium Flash Vaporization unit to remove the vac resid material. The entire 110 gallons of IBP-900F distillate, which contains HEDF precursor components as well as the vacuum gas oil (VGO) fractions, was composited and drummed for subsequent processing in the pilot plant fixed-bed hydrotreating unit for deep denitrogenation.

\subsection{Fixed-Bed Hydrodenitrogenation Operations}

The LC-Fining pilot plant unit was modified to be able to operate in the two-stage, downflow fixed-bed mode of hydroprocessing. The SHELL $324 M$ catalysts from the LC-Fining campaign were removed and replaced with Akzo Chemicals KF-843 NiMo catalyst designed for deep denitrogenation removal. Deep denitrogenation is required to protect the downstream zeolite-based VGO hydrocracking catalysts from poisoning by basic nitrogen compounds.

A total of 4000 cc of KF-843 catalyst was charged to each of the two fixed-bed reactors. The catalysts were calcined in situ at $750 \mathrm{~F}$ for two hours followed by presulfiding with a $2 \% \mathrm{H}_{2} \mathrm{~S} / \mathrm{H}_{2}$ gas mixture. After the presulfiding operations following the vendor's ${ }^{2}$ procedure, the unit was successfully pressure tested at 2500 psig.

The conditions selected for the HDN campaign were based on the screening test results of Subtask 3.2. These consisted of 2000 psig operating pressure, 785F average bed temperature, 2.0 LHSV per each of the two reactors and $3400 \mathrm{scfb}$ treat gas rate. The latter treat gas rate had to be reduced from the previously used $6000 \mathrm{scfb}$ because at the higher space velocity, the absolute flow rate limitations of the unit. Treat gas rate has been specified at a considerable excess over stoichiometry and it was not deemed detrimental to operate at the 3400 scfb rate. In both cases, hydrogen partial pressures are high and close to that of the system operating pressure. Table 4.3-1 summarizes the operating conditions and results.

The nitrogen content of the full-range hydrodenitrogenated VGO product was $31 \mathrm{ppm}$ vs $2185 \mathrm{ppm}$ for the feed representing an HDN rate of about 98.6\%. Sulfur content was reduced from $295 \mathrm{ppm}$ to $1 \mathrm{ppm}$. At the $785 \mathrm{~F}$ bed temperatures, there was a modest conversion of $575 \mathrm{~F}+$ equivalent to 23 wt\% with a corresponding chemical hydrogen consumption rate of 600 scfb. This hydrocracking achieved over the HDN catalyst represents a reduction in the severity of hydrocracking required in the downstream selective hydrocracking step for conversion of additional VGO components to HEDF precursors.

The net recovery of hydrotreated product at the completion of the HDN step was 118 gallons (approximately half of which was in the HEDF precursor boiling range). This material serves as the feedstock supply to the subsequent selective hydrocracking operations. 
RUN 6LCF-15 PRODUCTION RUN

FIXED BED HYDRODENITROGENATIO

OF 900F- COALITE-DERIVED LC-FINATE

\begin{tabular}{|c|c|}
\hline $\begin{array}{l}=======\quad======\quad===0 \\
\text { PERIOD NUMBER }\end{array}$ & $\begin{array}{l}=== \\
6 \mathrm{LCF}-15\end{array}$ \\
\hline DATE & $1 / 17$ \\
\hline TOTAL PRESSURE, PSIG & 2000 \\
\hline LHSV PER BED, 1/HOURS & 2.03 \\
\hline 1st STAGE AVG. BED TEMP., DEG. F & 781 \\
\hline 2nd STAGE AVG. BED TEMP., DEG. F & 788 \\
\hline AKZO KF-843 CATALYST AGE, & 0.179 \\
\hline TWO-STAGE WDSV, BBL/LB/DAY & 0.076 \\
\hline TREAT GAS (H2), SCF/BBL & 3400 \\
\hline CARBON BALANCE, WT.\% RECOVERY & 99 \\
\hline OVERALL MAT. BAL., WT.\% RECOVER & 98 \\
\hline
\end{tabular}

FEED PROPERTIES:

API GRAVITY

19.2

CARBON, WT.\%

88.55

HYDROGEN, WT.\%

11.06

SULFUR, pPm

295

NITROGEN, ppm

2185

OXYGEN, WT.\% (BY DIFFERENCE)

0.14

FULL-RANGE HDN PRODUCT PROPERTIES:

API GRAVITY

24.0

CARBON, WT.\%

88.37

HYDROGEN, WT.\%

11.63

SULFUR, ppm

NITROGEN, ppm

PRODUCT YIELDS, WT.\% FEED

OFFGAS H2S

0.03

OFFGAS NH3 $+\mathrm{H} 2 \mathrm{O}$

0.42

OFFGAS C1

0.44

OFFGAS C2

0.44

OFFGAS C3

OFFGAS C4

0.37

OFFGAS C5+

IBP-275 DEG. F

275-575 DEG. $F$

575 DEG. F +

TOTAL

$\begin{array}{rr} & 0.03 \\ & 0.42 \\ & 0.44 \\ & 0.44 \\ & 0.37 \\ \text { FEED } & 0.47 \\ -.- & 1.27 \\ 2.8 & 2.83 \\ 41.7 & 52.13 \\ 55.5 & 42.48 \\ 100.00 & 100.88\end{array}$

HYDROGEN CONSUMPTION, SCF/BBL 


\subsection{Fixed-Bed Selective Hydrocracking Operations}

The same reactor configuration as that used for the hydrodenitrogenation campaign was used for the selective hydrocracking operations. The objective of this campaign is to maximize the selective hydrocracking of $575 \mathrm{~F}+$ in the hydrodenitrogenated VGO material to high energy density, jet range components. During the Subtask 3.2 screening studies, three catalysts were evaluated and a proprietary zeolitic-based catalyst (manufactured by Zeolyst Enterprises, a joint venture of $P Q$ Corporation, Shell Polymers and Catalysts Enterprises), was selected as the preferred candidate on the basis of its simultaneous hydrocracking-hydrotreating performance. Thus, an additional hydrotreating step to saturate hydrocracked aromatics is avoided.

A total of $4000 \mathrm{cc}$ of $\mathrm{Z}-704 \mathrm{~A}$ catalyst was charged to each reactor. The unit was then successfully pressure tested at 1500 psig. The catalyst was dried in situ at 550F for 2 hours followed by reduction with hydrogen at $500 \mathrm{psig}$ and $750 \mathrm{~F}$ for 8 hours. Two operating severities were employed to allow production of two samples of HEDF test fuels.

The low severity condition was carried out at 500 psig hydrogen pressure, 1.16 LHSV per catalyst bed, 525F average bed temperature and treat gas rate of $5700 \mathrm{scfb}$. The high severity condition was carried out at 1000 psig hydrogen pressure and 650F average bed temperature. When excessive light ends make was observed, the bed temperatures were reduced to an average of 550F. Table 4.4-1 summarizes the operating conditions and results for both selective hydrocracking campaigns.

Performance as measured by extent of $H D N, 575 \mathrm{~F}+$ conversion and chemical hydrogen consumption rates was approximately equal. The major differences in the full-range hydrocracked products were the API Gravities and elemental hydrogen contents. While these differed only by a couple of API degrees and two-tenths of a percent hydrogen contents, respectively, these latter parameters can have significant effects on volumetric energy density and JFTOT stability.

\subsection{Post-Hydrotreatment Operations}

\subsubsection{Batch Fractionation}

The products from each campaign of the selective hydrocracking operations were fractionated in the pilot plant 4-in Batch Fractionation Unit as runs FBD-16 and FBD-17, respectively. The batch fractionation was operated to collect multiple narrow boiling fractions in the vicinity of the key cut points, namely, $280 \mathrm{~F}$ representing the front end volatility affecting the HEDF flash point specification, and $550 \mathrm{~F}$ representing the back end volatility affecting the viscosity and freeze point specifications.

The batch distillations were each carried out in two discrete operations: an atmospheric distillation from the initial boiling point up to $450 \mathrm{~F}$ distillate temperature followed by a $100 \mathrm{~mm} \mathrm{Hg}$ vacuum 
$========$

RUN NUMBER

PERIOD NUMBER

DATE

1991

TOTAL PRESSURE, PSIG

LHSV PER BED, 1/HOURS

1st STAGE AVG. BED TEMP., DEG. F

2nd STAGE AVG. BED TEMP., DEG. F

Z-704A CATALYST AGE, BBL

TWO-STAGE WDSV, BBL/LB/DAY

TREAT GAS (H2), SCF/BBL

CARBON BALANCE, WT.\% RECOVER

OVERALL MAT. BAL, WT.\% RECOVE
$====$

6LCF-16

$1 \& 2 \quad 3 \& 4$

-.... $\quad$-....

4/23-24 4/24-25

$500 \quad 1000$

$1.15 \quad 1.24$

$525 \quad 650-550$

$525 \quad 650-550$

$0.112 \quad 0.226$

$0.067 \quad 0.072$

$5700 \quad 5300$

$99 \quad 98$

$99 \quad 98$

FEED PROPERTIES:

$\begin{array}{lrr}\text { API GRAVITY } & 24.0 & 24.0 \\ \text { CARBON, WT.\% } & 88.37 & 88.37 \\ \text { HYDROGEN, WT.\% } & 11.63 & 11.63 \\ \text { SULFUR, ppm } & 1 & 1 \\ \text { NITROGEN, ppm } & 31 & 31 \\ \text { OXYGEN, WT.\% (BY DIFFERENCE) } & 0 & 0\end{array}$

FULL-RANGE HYDROCRACKATE PRODUCT PROPERTIES:

$\begin{array}{lrr}\text { API GRAVITY } & 36.3 & 38.5 \\ \text { CARBON, WT.\% } & 86.45 & 86.28 \\ \text { HYDROGEN, WT.\% } & 13.55 & 13.72 \\ \text { SULFUR, ppm } & <1 & <1 \\ \text { NITROGEN, ppm } & <1 & <1\end{array}$

PRODUCT YIELDS, WT.\% FEED

OFFGAS H2S
OFFGAS NH3 + H2O
OFFGAS C1
OFFGAS C2
OFFGAS C3
OFFGAS C4
OFFGAS C5+
IBP.275 DEG. F
275-575 DEG. F
575 DEG. F +
TOTAL

$\begin{array}{rrr} & 0.00 & 0.00 \\ & 0.00 & 0.00 \\ & 0.68 & 0.63 \\ & 0.68 & 0.62 \\ & 0.58 & 0.53 \\ \text { FEED } & 0.73 & 0.67 \\ \ldots . . & 1.96 & 1.80 \\ 2.9 & 12.82 & 19.49 \\ 53.5 & 73.30 & 68.10 \\ 43.6 & 11.74 & 10.83 \\ 100.00 & 102.49 & 102.66\end{array}$

HYDROGEN CONSUMPTION, SCF/BBL $\quad 1500 \quad 1600$ 575 DEG F+ CONVERSION, WT.\% $\quad 73 \quad 75$ HYDRODENITROGENATION, \% REM $\quad 100 \quad 100$ HYDRODESULFURIZATION, \% REMO $\quad 100 \quad 100 \quad 42$ 
distillation up to $610 \mathrm{~F}$ atmospheric equivalent distillate temperature. Table 4.5.1-1 presents the summary of the distillate fractions and corresponding yields. As expected, the product from the low severity hydrocracking operation contained the highest yield of 610F+ (unconverted) material.

\subsubsection{Distillate Product Blending}

The distillate cuts from each batch fractionation run were blended in proportion to their overall batch fractionation yields to generate small samples for analytical testing of flash point, freeze point and energy density. As shown in Table 4.5.2-1, the heart cut HEDF blend (280-550F) met the flash point specification. Subsequent aliquot blends were made by adding the narrow boiling cuts above the $550 \mathrm{~F}$ point and checking freeze point. Volumetric energy density increases with end point while freeze point also increases. The hydrogen content however decreases which is directionally adverse to good JFTOT stability. Because of the large sample quantity and cost of the JFTOT test, only selected blends were subjected to JFTOT testing.

Based on these results, it was decided that the preferred HEDF boiling range is 280-580F for both the low severity and high severity hydrocrackates. The full quantity distillate blends having the 280-580F boiling range were made from all the materials fractionated in the four-in batch fractionation unit.

\subsubsection{Clay Treating}

Clay treating is a process aimed at removing trace polar compounds that could have an adverse effect on fuel stability. It is practiced commercially in refineries for petroleum-based aviation turbine fuels. Many types of clays can be used and we selected bentonite for this program. A total of $4500 \mathrm{cc}$ of bentonite clay was charged to the pilot plant clay treating column.

Both the low severity and high severity materials were treated by clay treating. The conditions selected for the pilot plant clay treating unit were based on some laboratory screening studies of clay treating using a small diameter glass column. These conditions consisted of operation at ambient temperature, 4 psig pressure with a liquid percolation rate of $1.3 \mathrm{gph}$ equivalent to a bentonite space velocity of $1.2 \mathrm{gal} / \mathrm{hr} / \mathrm{gal}$. The results of the batch-continuous clay treating operations are presented in Table 4.5.3-1. The loss of material of about $1 \%$ was primary a result of liquid holdup in the packed bed as well as physical adsorption of polar compounds in the HEDF test fuel. In a true continuous process, the holdup component, which represents the bulk of the apparent loss of material, would be a very small fraction of the total liquid processed. 
TABLE 4.5.1-1

BATCH DISTILATION OF

HYDROTREATED COALTE PRODUCTS FROM

SELECTIVE HYDROCRACKING RUN GLCF-16

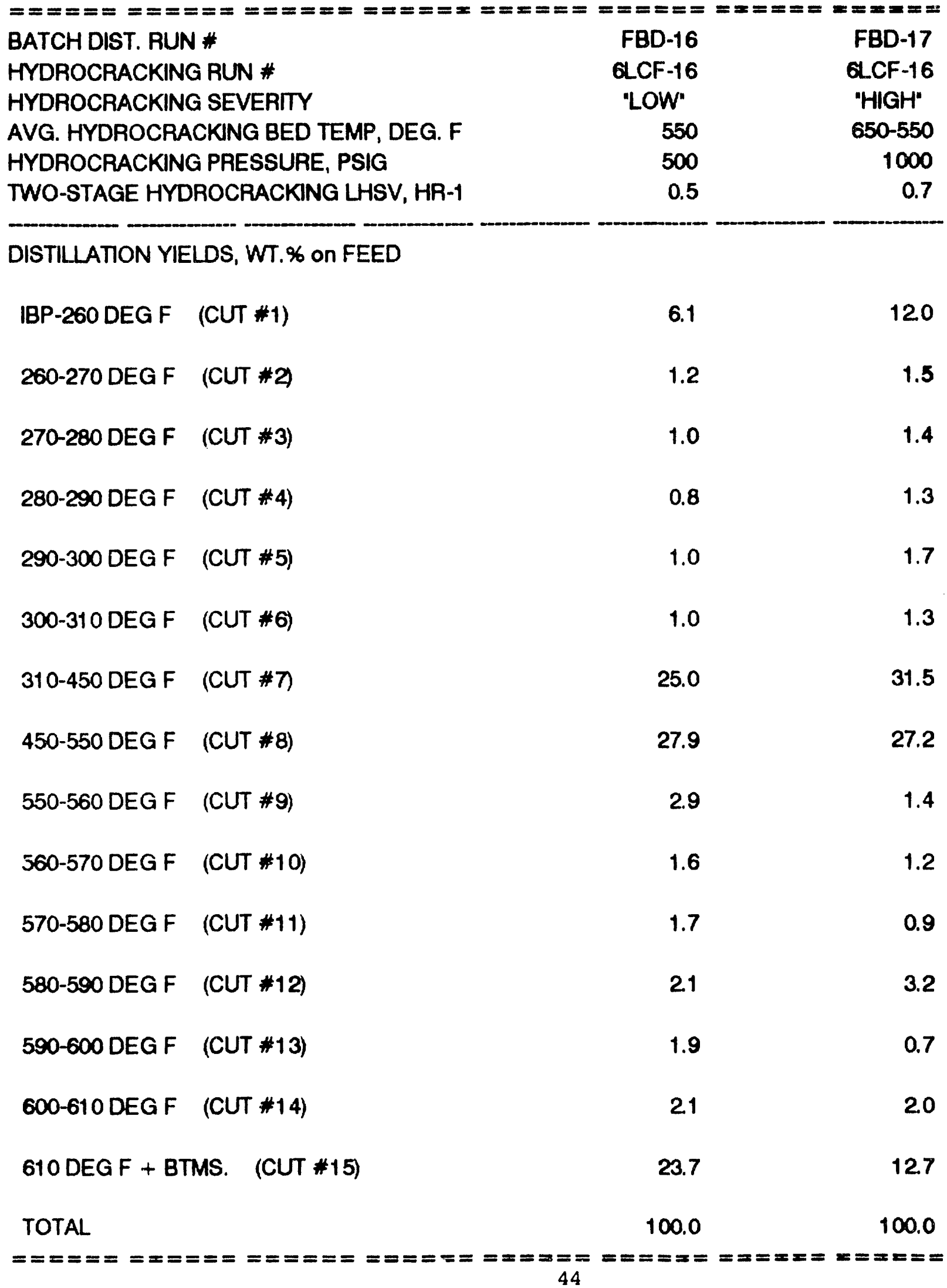


TABLE 4.5.2-1

OPTIMUM BLENDING STUDY OF

FINISHED COALTE JET FUEL CUTS

FROM FBD-16 \& FBD-17

\begin{tabular}{|c|c|c|c|c|c|c|}
\hline $\begin{array}{l}=========== \\
\text { HEDF BOILING RANGE }\end{array}$ & $\begin{array}{l}==== \\
\text { FLASH } \\
\text { POINT } \\
\text { DEG. F }\end{array}$ & $\begin{array}{c}===== \\
\text { FREEZE } \\
\text { POINT } \\
\text { DEG. F }\end{array}$ & $\begin{array}{c}===== \\
\text { GRAVITY } \\
@ 60 / 60 \\
\text { gm/cc }\end{array}$ & $\begin{array}{c}===== \\
\text { CARBON } \\
\text { WT. } \%\end{array}$ & $\begin{array}{c}x=x=== \\
\text { HYDROGE } \\
\text { WT. } \%\end{array}$ & $\begin{array}{l}===== \\
\text { ENERGY } \\
\text { DENSITY } \\
\text { BTU/Gal }\end{array}$ \\
\hline \multicolumn{7}{|c|}{ FBD-16:LOW SEVERITY HYDROCRACKATES } \\
\hline $280-550 \mathrm{~F}$ & 130 & $<-85$ & 0.8565 & 86.29 & 13.37 & 131,460 \\
\hline $280-560 \mathrm{~F}$ & - & $<-85$ & 0.8581 & 86.25 & 13.35 & 131,962 \\
\hline $280-570 \mathrm{~F}$ & - & $<-85$ & 0.8591 & 86.57 & 13.36 & 131,766 \\
\hline $280-580 \mathrm{~F}$ & - & -76 & 0.8602 & 86.20 & 13.30 & 132,140 \\
\hline $280-590 \mathrm{~F}$ & - & -72 & 0.8607 & 86.31 & 13.29 & 132,036 \\
\hline $280-600 \mathrm{~F}$ & - & -67 & 0.8623 & 86.36 & 13.23 & 132,525 \\
\hline $280-610 \mathrm{~F}$ & - & -63 & 0.8633 & 86.26 & 13.18 & 132,523 \\
\hline 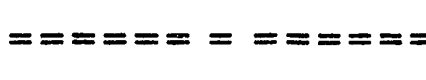 & $====$ & $=====$ & $=====$ & $=====$ & $==\boldsymbol{=}=\mathbf{=}$ & $=====$ \\
\hline \multicolumn{7}{|c|}{ FBD-17: HIGH SEVERITY HYDROCRACKATES } \\
\hline $280-550 \mathrm{~F}$ & 125 & $<-85$ & 0.8473 & 86.24 & 13.55 & 127,677 \\
\hline $280-560 \mathrm{~F}$ & - & $<-85$ & 0.8473 & 85.83 & 13.49 & 130,350 \\
\hline $280-570 \mathrm{~F}$ & - & -85 & 0.8488 & 86.22 & 13.51 & 130,625 \\
\hline $280-580 \mathrm{~F}$ & - & -72 & 0.849 .3 & 86.25 & 13.51 & 130,858 \\
\hline $280-590 \mathrm{~F}$ & - & -63 & 0.8514 & 85.95 & 13.51 & 131,011 \\
\hline $280-600 \mathrm{~F}$ & - & -58 & 0.8514 & 85.87 & 13.53 & 130,927 \\
\hline $280-610 \mathrm{~F}$ & - & -49 & 0.8524 & 86.00 & 13.45 & 130,863 \\
\hline
\end{tabular}


TABLE 4.5.3-1

BENTONITE CLAY TREATING

OF HEDF FUEL BLENDS

\section{TEST FUEL DESIGNATION}

FBD-16

FBD-17

COLUMN I.D., in.

2.3

2.3

COLUMN SURFACE AREA, in2

4.15

4.15

COLUMN SURFACE AREA, It2

0.029

0.029

BENTONITE CLAY :

VOLUME, CC

4500

4000

VOLUME, gal

1.19

1.06

WEIGHT, IbS. START

8.28

7.31

WEIGHT, IbS. END

10.47

2.19

10.77

PICKUP WEIGHT, IbS.

DOWN

DOWN

TREATMENT PRESSURE, psig
PACKED BED FLOW DIRECTION

1.33

9.53

1.30

FEED RATE, GPH

1.12

9.45

LHSV, 1/HR

207.50

1.23

FEED IN, Ibs.

205.21

PRODUCT OUT, IbS.

APPARENT LOSS, Ibs*

2.29

208.00

205.50

APPARENT \% LOSS*

1.1

250

1.2

* Apparent Loss Consists of Liquid Holdup in Interstices of Clay Bed

Plus Adsorbed Trace Polar Compounds 


\subsection{HEDF ASSAYS}

The bentonite-treated HEDF products were stored ir clean 30-gallon drums with about 25-gal of each sample type (low severity hydrocracking and high severity hydrocracking) available for delivery to DOE-METC and/or its contractors. Representative samples were taken for assay. The results are summarized in Table 5-1.

The volumetric energy ensities for the two samples were 130, 1506 Btu/gal for the high severity hydrocracking route and 131,740 for the low severity route, both meeting the original Work Statement energy density target of $130,000 \mathrm{Btu} / \mathrm{Gal}$ min. Subsequent to the original Statement of Work, DOE set a new technical goal of achieving an energy density target of $135,000 \mathrm{Btu} / \mathrm{gal}$. As can be seen from Table 4.5.2-1, energy densities for the low severity hydrocracking sample increased with distillate end point to a high value of $132,523 \mathrm{Btu} / \mathrm{gal}$ $0610 \mathrm{~F}$ end point vs the 580F value for the test fuel sample. Even higher values can be achieved depending upon hydroprocessing reaction conditions. During the Subtask 3.2 screening program, four tests were made in bench-scale equipment and energy densities as high as 133,992 Btu/gal were achieved. Table 5-2 summarizes the properiies of the HEDF fuels generated in that program.

Although the highest volumetric energy density is desired, there are two other criteria to consider. The first is a function of economics and the resultant tradeoffs between the additional cost of the incremental energy density improvement vs the value of the higher density fuel to the end user. This is a subject briefly discussed in the Task 4 topical report (4). The other criteria concerns the storage stability and thermal stability of the fuel for use in high speed aircraft. One analytical device for assessing stability performance is the Standard Test Method for Thermal 0xidation Stability of Aviation Turbine Fuels (JFTOT Procedure, ASTM D3241-85). JFTOT subjects the test fuel to conditions that are relatable to those occurring in gas turbine engine fuel systems. The fuel is pumped at a fixed volumetric flow rate through a heater after which it enters a precision stainless steel filter where fuel degradation products become trapped. The essential data derived are the amount of deposits on an aluminum heater tube and the rate of plugging of a 17 micron nominal porosity filter located just downstream of the heater tube. This test has long been used by petroleum refiners to meet process specifications for shipment of aviation fuel products to the end users, namely, the commercial airline industry and the U.S. Air Force. With the advent of new aircraft engines and new fuel compositions, the JFTOT test is not always an accurate gauge for assessing on-board fuel stability performance. The Air Force is continually improving technology for on-ground determination of thermal stability of aviation turbine fuels. With regard to the new fuel type, High Energy Density (Category I) fuel, it is not known how applicable the JFTOT test will be for assessing thermal stability. 
FMAL CONUTE HEDF TEST FUEL PROPERTES*

$z= \pm x=m= \pm=$ DEEKantion

CAAVT, SP. @ CONO0

CRAVTr. DEO. API

\section{FBD-16 FBD-18}

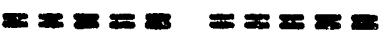

0.8501

33.2

Q.encos

34.1

ELEMENTAL8, WT.\%

CARBON

82.63

MMOROCEN

0260

13.41

F.I.A. VOL\%

AROMATCS

OLEFMS

SATURATE8

FLASH PONT, DEQ. F

FREEZE PONT, DEQ. F

AMINE PONT, DEO. C

ENOKE PONT, mm

Vecosry, cat@-4F

COPPER CORROSKON, @212F

POTENTLL GUM, mo/100 m

D2274 ACCEL STORMCE STABUTY

(@95x, $16 \mathrm{Ht}, 02$ ), mo/1 DO ml

THEFMAL 8TABUTY (JFTOT-D3241)

TUEE DEPOOIT VEUNL RATMO(TDA)

TUBE DEPOQIT RATMO MUX EPUN PAT

DFFERENTML PREBQURE MAX, mn to

ENEAOY DENATY, BTU/ONLON
1.2

0.3

0.4

8.5

130

$<-76$

00.8

25

0.7

20

120

$<-78$

04.4

7.0

7.5

$3 n$

$1 A$

$<1$

$<1$

$<1$

$<1$ 1 
TABLE 5-2

COALITE DERIVED

HEDF PUEL PROPERTIES

TASK 3 SCREENING PROGRAM RESULTS

DESIGNATION

BOILING RANGE, DEG. F
FBHC-41

$300-600$
FB-214D

300-610
FB-214E

$300-620$
FB-214F

$300-600$
GRAVITY, SP. @60

GRAVITY, DEG. API

ELEMENTALS:

CARBON, WT.\%

HYDROGEN, WT.\%

NITROGEN, ppm

SULFUR, ppm

VISCOSITY@-4F, cst.

FLASH POINT, DEG. F

FREEZE POINT, DEG. F

SMOKE POINT, $\mathrm{mm}$

ANILINE POINT, DEG. C

F.I.A.:

AROMATICS, VOL.\%

OLEFINS, VOL.\%

SATURATES, VOL.\%

COPPER CORROSION,@212F

POTENTIAL GUM, mg/100ml

THERMAL STABILITY (JFTOT):

TUBE DEPOSIT RATING

TUBE DEPOSIT RATING, MAX.

DIFF. PRESS. MAX., $\mathrm{mm} \mathrm{Hg}$

$\begin{array}{rrrr}0.8560 & 0.8745 & 0.8571 & 0.8702 \\ 33.8 & 30.3 & 33.6 & 31.1\end{array}$

86.36

13.64

$<1$

5

9.1

14.1

9.3

11.0

$>120$

$>145$

$>140$

$>150$

$<-50$

$<-50$

$<-50$

$<-50$

22

18

20

20

61.9

58.0

62.0

54.9

4.6

0.5

94.9

\section{7}

0.5

95.8

1A

$1 A$

6.6

0.5

15.2

92.9

0.5

84.3

3A

7.0

NA

7.4

16.4

ENERGY DENSITY, BTU/GAL

$\begin{array}{rrrr}0 & 0 & 0 & 2 \\ 0.5 & 1.0 & 1.5 & 8.0 \\ 3.0 & 3.0 & 3.0 & 3.0\end{array}$


TABLE 5-2

COALITE DERIVED

HEDF FUEL PROPERTIES

TASK 3 SCREENING PROGRAM RESULTS

\begin{tabular}{|c|c|c|c|c|}
\hline $\begin{array}{l}\text { DESIGNATION } \\
\text { BOILING RANGE, DEG. F }\end{array}$ & $\begin{array}{c}\text { FBHC-41 } \\
300-600\end{array}$ & $\begin{array}{r}\text { PB-214D } \\
300-610\end{array}$ & $\begin{array}{r}\text { FB-214E } \\
300-620\end{array}$ & $\begin{array}{r}\text { PB-214F } \\
300-600\end{array}$ \\
\hline GRAVITY, SP. @60 & 0.8560 & 0.8745 & 0.8571 & 0.8702 \\
\hline GRAVITY, DEG. API & 33.8 & 30.3 & 33.6 & 31.1 \\
\hline \multicolumn{5}{|l|}{ ELEMENTALS: } \\
\hline CARBON, WT.\% & 86.36 & 86.84 & 86.55 & 86.78 \\
\hline HYDROGEN, WT.\% & 13.64 & 13.16 & 13.45 & 13.22 \\
\hline NITROGEN, ppm & $<1$ & $<1$ & $<1$ & $<1$ \\
\hline SULPUR, ppm & 5 & 4 & 1 & $<1$ \\
\hline VISCOSITY@-4P,cst. & 9.1 & 14.1 & 9.3 & 11.0 \\
\hline FLASH POINT, DEG. $F$ & $>120$ & $>145$ & $>140$ & $>150$ \\
\hline FREEZE POINT, DEG. F & $<-50$ & $<-50$ & $<-50$ & $<-50$ \\
\hline SMOKE POINT, mm & 22 & 18 & 20 & 20 \\
\hline ANILINE POINT, DEG. C & 61.9 & 58.0 & 62.0 & 54.9 \\
\hline \multicolumn{5}{|l|}{ F.I.A.: } \\
\hline AROMATICS, VOL.\% & 4.6 & 3.7 & 6.6 & 15.2 \\
\hline OLEFINS, VOL.\% & 0.5 & 0.5 & 0.5 & 0.5 \\
\hline SATURATES, VOL.\% & 94.9 & 95.8 & 92.9 & 84.3 \\
\hline COPPER CORROSION, @ 212F & $3 \mathbf{A}$ & $1 \mathrm{~A}$ & $1 \mathrm{~A}$ & $1 \mathrm{~A}$ \\
\hline POTENTLAL GUM, $\mathrm{mg} / 100 \mathrm{ml}$ & 7.0 & NA & 7.4 & 16.4 \\
\hline \multicolumn{5}{|l|}{ THERMAL STABILITY (JFTOT): } \\
\hline TUBE DEPOSIT RATING & 0 & 0 & 0 & 2 \\
\hline TUBE DEPOSIT RATING, MAX. & 0.5 & 1.0 & 1.5 & 8.0 \\
\hline DIFF. PRESS. MAX., mm Hg & 3.0 & 3.0 & 3.0 & 3.0 \\
\hline ENERGY DENSITY, BTU/GAL & 130,860 & 133,992 & 131,622 & 132,901 \\
\hline
\end{tabular}


In any event, JFTOT testing (as well as Potential Gum and Accelerated Storage Stability) was used to assess fuel stability. Directionally, increasing fuel end point to increase specific gravity and volumetric energy density is inversely proportional to stability. The JFTOT stability criterion, Maximum Heater Tube Deposit/Visual Rating (TDR), was 0 for both the high severity and the low severity hydrocracking routes, both meeting the spec for conventional JP-8 turbine fuel. The specs for the JFTOT stability criterion of Change in Pressure Drop were not met. However, the specs for both Accelerated Storage Stability and Potential Gum were met.

In view of the JFTOT pressure drop results, aliquots of the test fuel samples were rerun through the laboratory clay treating column and the resultant samples were analyzed for JFTOT. These samples passed both the TDR criterion and the pressure drop criterion. It was concluded that there were some trace polar compounds in the HEDF test fuels that were not removed in the pilot plant clay treating unit as a result of a hydrodynamic bypassing of material in the column. Probably optimization of the liquid contacting efficiency in the pilot plant clay treating unit, such as by operating at higher Reynolds Numbers or by recycling material through multiple passes, would result in the clay-treated material passing both JFTOT criteria. Unfortunately, the 50 gallons of test fuel could not be scheduled to be rerun.

The finished HEDf test fuels after the clay treating operations were dosed with the following additives while in storage awaiting shipment to DOE-METC:

o BHT (anti-oxidant)

- DCI $-4 A$ (DuPont corrosion inhibitor)
$24 \mathrm{mg} / \mathrm{L}$

$20 \mathrm{mg} / \mathrm{L}$ 


\subsection{REFERENCES}

1. Pound, G.S., "The Production of Chemicals From Low Temperature Tar", J.Inst. Fuels, Coke \& Gas (October 1952)

2. Char 0 il Energy Development (COED), FMC Corp Contractor, ERDA(DOE) Contract $E(49-18)-1212$, \#FE/1212/F, (Sept 1975)

3.Khan, M.R., "Correlations Between Physical \& Chemical Properties of Pyrolys is Liquids", Energy \& Fuels, 2, 1988, pp. 834

4. "Development of High Energy Fuels From Mild Gasification of Coal", DOE Contract DE-AC21-88MC25020, Task 4 Topical Report (October 1990) 


\subsection{ACKNOWLEDGEMENTS}

$A B B$ Lummus Crest would like to acknowledge the technical guidance of Charles Byrer, DOE-METC Contracting Officer's Technical Representative. We would also like to acknowledge the efforts of the following Lummus personnel involved on the Task 5 program:

Marvin Greene, Project Manger/Principal Investigator

Robert Valente, Research Engineer in charge of Task 5 pilot plant operations

Sam Mikhail, Supervisor of Analytical Services. 

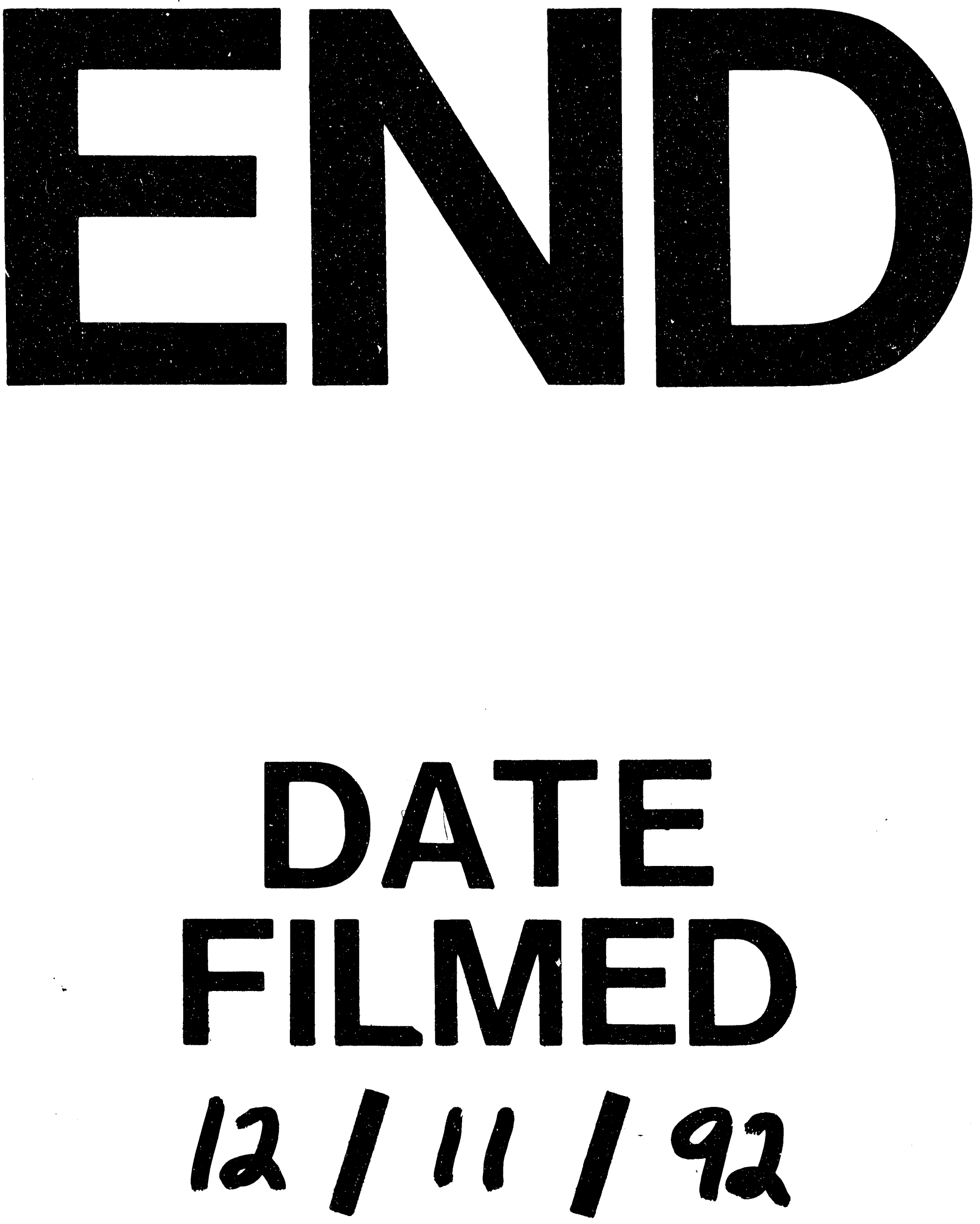
